\title{
Male, National, and Religious Collective Narcissism Predict Sexism
}

\author{
Agnieszka Golec de Zavala ${ }^{1,2,3}$ (1) $\cdot$ Kinga Bierwiaczonek ${ }^{2,4,5}$
}

Accepted: 8 September 2020 / Published online: 5 October 2020

(C) The Author(s) 2020

\begin{abstract}
Results of three cross-sectional studies indicate that sexism in Poland is associated with collective narcissism - a belief that one's own group's (the in-group's) exaggerated exceptionality is not sufficiently recognized by others - with reference to three social identities: male, religious, and national. In Study $1(n=329)$, male collective narcissism was associated with sexism. This relationship was sequentially mediated by precarious manhood and traditional gender beliefs. In Study $2(n=877)$, Catholic collective narcissism predicted tolerance of violence against women (among men and women) over and above religious fundamentalism and in contrast to intrinsic religiosity. In Study $3(n=1070)$, national collective narcissism was associated with hostile sexism among men and women and with benevolent sexism more strongly among women than among men. In contrast, national in-group satisfaction - a belief that the nation is of a high value - predicted rejection of benevolent and hostile sexism among women but was positively associated with hostile and benevolent sexism among men. Among men and women collective narcissism was associated with tolerance of domestic violence against women, whereas national in-group satisfaction was associated with rejection of violence against women.
\end{abstract}

Keywords Collective narcissism $\cdot$ Sexism $\cdot$ Violence against women $\cdot$ Gender $\cdot$ Religion $\cdot$ National identity

\section{Three Types of Collective Narcissism-Male, Religious, and National-Predict Sexism in Poland}

The mass-shooting that took place at the University of California in 2014 was explicitly motivated by hatred of women (BBC News 2018). Unlike interpersonal violence against women

Data, codes for analyses and a detailed description of procedures and measures can be found at https://osf.io/jafgh/?view_only= 72e5e7ada88b4d1e8cc3653f371f130f

Electronic supplementary material The online version of this article (https://doi.org/10.1007/s11199-020-01193-3) contains supplementary material, which is available to authorized users.

Agnieszka Golec de Zavala agnieszka.golec@gmail.com

1 Department of Psychology, Goldsmiths, University of London, New Cross, London SE14 6NW, UK

2 SWPS University of Social Sciences and Humanities, Poznan, Poland

3 Instituto Universitário de Lisboa, ISCTE-IUL, Lisbon, Portugal

4 Department of Psychology, University of Oslo, Oslo, Norway

5 VU University Amsterdam, Amsterdam, Netherlands
(Bushman et al. 2003; Fowler and Westen 2011; Mouilso and Calhoun 2016; Zeigler-Hill et al. 2013), hate crimes against women and sexism (prejudice toward and discriminatory treatment of women as a social group; Glick and Fiske 1997, 2001) are unlikely to be motivated by individual narcissism (a personality trait defined by self-importance and need for admiration; Morf et al. 2011). Instead, they may be driven by frustrated narcissistic entitlement elevated to a group level, which takes a form of collective narcissism that is, a belief that one's own group's (the in-group's) exaggerated exceptionality is not sufficiently recognized by others (Golec de Zavala et al. 2009, 2019; Golec de Zavala and Lantos 2020). Indeed, the University of California shooter spoke for "Incels" (i.e., self-proclaimed "involuntary celibates"), an online community of sexually frustrated men preaching hate and vengeance toward women for not recognizing their entitlement to have sex with the women they choose (Beauchamp 2019; Williams 2018).

Collective narcissism is positively associated with individual narcissism, but only collective narcissism uniquely predicts intergroup hostility and prejudice (for a metanalysis see Golec de Zavala et al. 2019). In addition, national collective narcissism in many countries is associated with right-wing populism (Golec de Zavala and Keenan 2020) that moralizes and advocates gender inequality (Korolczuk and Graff 2018). 
Research has also suggested that male collective narcissism thwarts empathy toward and solidarity with women who are perceived as a threatening out-group (Górska et al. 2019). The present studies extend the previous research by examining, for the first time known, the associations among collective narcissism and hostile (derogatory and antagonistic beliefs about women as a social group rooted in intergroup-level competition of men with women) and benevolent sexism (paternalistic prejudice based on the belief that women are passive and incompetent and should be protected). Although positive in tone, benevolent sexism is positively associated with hostile sexism and has multiple negative consequences (Glick and Fiske 1997, 2001).

Extending previous research, we examine (a) whether male collective narcissism is associated with sexism via the perception of the gender in-group as threatened. Next, going beyond the intergroup perspective, we argue that collective narcissism is associated with sexism among men and women when collective narcissism pertains to broader, superordinate categories, which men and women share. Specifically, we examine (b) whether sexism is associated with national and religious collective narcissism among men and women in Poland. We also (c) examine gender moderation on those associations. Finally, we test (d) whether the association with sexism is specific to male, religious, and national collective narcissisms in comparison to variables pertaining to alternative positive beliefs about those social categories that collective narcissism can be differentiated from male: in-group satisfaction, religious orientations, and national in-group satisfaction, respectively.

We test these predictions in Poland, where women face the most restrictive anti-abortion laws in Europe, and their access to sexual and reproductive healthcare and information is limited. The ultra-conservative Polish government systematically harasses women activists. Supported by the Polish Catholic Church, it stigmatizes women activists, along with all men and women who refuse to conform to traditional gender roles (Amnesty International 2019; Human Rights Watch 2019). Studies and analyses indicate that ultraconservative populists in Poland see gender equality as a threat to and a foreign "colonization" of traditional national identity (Korolczuk and Graff 2018, p. 797). In this vision of national identity, which attributes national prototypically to ethnically Polish, Catholic, heterosexual men, gender hierarchy is moralized and women are relegated to second-class citizenship (Graff 2010; Kościańska 2014a, b; Mole et al. 2020). As we mentioned, collective narcissism defines the ultra-conservative vision of national identity in Poland. More generally, national collective narcissism is associated with derogation of those disadvantaged in-group members whose emancipation threatens traditional societal hierarchies (Golec de Zavala and Keenan 2020). This suggests that men and women who hold collective narcissistic belief about Polish national or religious in-group may endorse sexism.

\section{Intergroup Perspective: Male Collective Narcissism and Sexism}

In line with previous research indicating that collective narcissism is related to prejudice toward out-groups perceived as threatening (Dyduch-Hazar et al. 2019; Golec de Zavala et al. 2009; Lyons et al. 2010), studies showed that male collective narcissism (but not nonnarcissistic positive gender identification) was associated with perceived threat from women (Górska et al. 2019). Previous research has also shown that collective narcissism is associated with intergroup hostility because of the perception of the in-group as threatened (Golec de Zavala et al. 2009; Golec de Zavala and Cichocka 2012). Given this evidence, we argue that male collective narcissism is likely to be associated with sexism. Moreover, this association is likely to be driven by men perceiving their gender identity to be threatened.

We expect that the relationship between male collective narcissism and sexism will be mediated by precarious manhood, the belief in manhood is a form of social status that needs to be earned through repeated demonstrations of masculinity (Bosson and Vandello 2011, 2013; Vandello et al. 2008). Men may endorse sexism because they attempt to ground the volatile status of their manhood in traditional beliefs about gender roles that sanction the privileged status of men over women.

Indeed, men who perceive their gender status as precarious feel motivated to restore it by engaging in stereotypically male behaviours (Bosson and Vandello 2011; Vandello et al. 2008), which help them to down-regulate negative mood when their manhood is threatened (Bosson et al. 2009). Precarious manhood predicts lower willingness to confront sexual prejudice (Kroeper et al. 2014), expressing amusement at sexist jokes (O'Connor et al. 2017), and feeling threatened by women superiors at work (Netchaeva et al. 2015). In addition, when their gender prototypicality is threatened, men are more likely to harass women (Maass et al. 2003). In Poland, men believe more strongly than women that the definition of gender roles should be grounded in national and religious traditions (Mole et al. 2020).

Given this evidence, we predict that collectively narcissistic men (compared to men more satisfied with their gender) may feel uncertain about their masculinity and they may be motivated to uphold a belief system that stabilizes their status within a traditional gender hierarchy. This belief system justifies sexism. It is supported by the dominant populist narrative about national identity in Poland rooted in associations with traditional Catholic values (Graff 2010; Mole et al. 2020). Thus, we expected that Catholic and national collective narcissism also may be linked to sexism in Poland. 


\section{Common Identity Perspective: Religious Collective Narcissism and Sexism}

Scholars have linked Catholic religious institutions to legitimizing and promoting gender hierarchy (Buss and Herman 2003; Case 2011). Psychological studies have linked Catholic religiosity to sexism (Glick, Lameiras, \& Rodriguez Castro, 2002; in Poland, Mikołajczak and Pietrzak 2014) and showed that priming Catholic religious identity increased benevolent sexism and acceptance of gender inequality among men and women (Haggard et al. 2019). However, studies also suggest that Catholic religiosity may be related to egalitarian values and tolerance (Hansen et al. 2018). We propose that the dual function of religion needs to be taken into account for a better understanding of the association between religiosity and sexism.

Religion may be seen as a social identity where religiosity indicates identification with the in-group defined by a common religion (Hogg et al. 2010). Catholic collective narcissism as a positive belief about religious social identity may be associated with sexism. Indeed, Catholic collective narcissism in Poland is positively associated with traditional beliefs about gender roles (Mole et al. 2020). It also predicts a belief that proponents of "gender ideology" conspire against the traditional family values at the core of the Polish national identity (Marchlewska et al. 2019). Thus, Catholic collective narcissists may see gender equality as a threat to the positive image of Catholics as a social group.

However, religion is also a belief system that offers normative prescriptions for behaviour including tolerance and equal treatment of others. Thus, the association between religiosity and sexism is likely to depend on how individuals resolve the dual function of religion. Members of religious groups vary in how literally they understand religious teaching and what their motivations to follow it are. Religious fundamentalism (i.e., a belief that literally understood religious teachings are infallible and the sole repository of fundamental truths that must be obeyed in accordance with tradition; Kirkpatrick and Locke 1991; Altemeyer and Hunsberger 1992) is linked to sexism regardless of the type of religion (Hannover et al. 2018). However, intrinsic religiosity (i.e., treating religious faith as an intrinsic end in itself) is negatively associated with hostile sexism (Burn and Busso 2005). More generally, intrinsic religiosity is negatively associated with prejudice, whereas extrinsic religious orientation (treating religious faith as instrumental to ends such as social identity, belonging or social status) is positively associated with prejudice (Batson et al. 1986).

Such findings suggest that the role of religious collective narcissism as a predictor of sexism should be considered in comparison to religious orientations to clarify the role of each of them in light of contradictory findings. For example, some studies indicate that intrinsic religious orientation is associated with tolerance toward minorities, unlike religious fundamentalism and extrinsic religious orientation which predict racism, sexism or homophobia (Kirkpatrick 1993). However, other studies suggest that extrinsic and intrinsic religious orientations predict prejudice toward gay men and lesbians because rejection of those groups is prescribed by religious teaching (Herek 1987).

\section{Common Identity Perspective: National Collective Narcissism and Sexism}

Like any prejudice, sexism is a function of normative beliefs fostered not only by religions but also maintained by nations, which both genders represent (Crandall et al. 2002; Jost and Banaji 1994; Kay et al. 2009; North and Fiske 2014; Sidanius and Pratto 1999). Both men and women are more likely to endorse sexism when they perceive it as normative and gender inequality as desirable (Sibley et al. 2007a). More generally, people are more likely to adhere to normative beliefs of groups they identify with and treat this adherence as an expression of positively valued social identity (Ellemers et al. 2013). Studies also suggest that positive identification with a common, superordinate identity increases acceptance of beliefs justifying normative group-based inequalities among advantaged (Lowery et al. 2006) and disadvantaged sub-groups (Dovidio et al. 2007, 2009;).

However, even within the same nation, normative prescriptions regarding gender equality are unlikely to be uniform. Just as different attitudes toward the gender hierarchy may be prescribed by different religious orientations, they also may be prescribed by different beliefs about the same national identity. Beliefs conveying the prescription of equality and tolerance are more likely to be associated with rejection of sexism, whereas beliefs conveying intergroup antagonism and hierarchy are likely to be positively associated with sexism. National collective narcissism and national in-group satisfaction are alternative positive beliefs about the same nation. National in-group satisfaction is a belief that membership in the nation is good and a reason to be proud (Leach et al. 2008; it has also been named private collective self-esteem, Crocker and Luhtanen (1990) or, with reference to a national in-group, genuine or constructive patriotism (Adorno et al. 1950; Kosterman and Feshbach 1989; Schatz et al. 1999; Staub 1997). Studies suggest that national collective narcissism and national in-group satisfaction convey different prescriptions regarding intergroup attitudes and attitudes toward minorities within the nation (for review see, Golec de Zavala et al. 2019; Golec de Zavala and Lantos 2020).

Collective narcissism prescribes distrust and hostility as normative in intergroup relations, whereas national in-group satisfaction prescribes equality and intergroup tolerance, especially after its overlap with collective narcissism is partialled 
out (Golec de Zavala et al. 2016, 2020). Whereas collective narcissism predicts intergroup hostility in response to perceived threat to the in-group's positive image, in-group satisfaction does not (Golec de Zavala et al. 2013b). Whereas collective narcissism is associated with prejudice toward minorities (ethnic, Lyons et al. 2010; sexual, Mole et al. 2020), national in-group satisfaction is not (Golec de Zavala et al. 2013a, 2020). Collective narcissism is associated with hypersensitivity to national image threat (Golec de Zavala et al. 2016), whereas national in-group satisfaction is associated with acceptance of criticism and the possibility that the national ingroup can be improved (Golec de Zavala et al. 2013a, b). In addition, in Poland, the belief that nontraditional women and gender equality threaten the national identity is positively associated with national collective narcissism and negatively associated with national in-group satisfaction (Mole et al. 2020).

Going beyond the previous findings, we expect that unlike national in-group satisfaction, national collective narcissism may be positively associated with hostile sexism including tolerance of domestic violence against women. Additionally, we expect that gender may moderate the specific association between beliefs about national identity (collective narcissism vs. in-group satisfaction) and benevolent sexism because men and women find benevolent sexism more acceptable than hostile sexism due to its superficial positivity (Glick and Fiske 2001). Thus, men and women are more likely to adopt benevolent sexism to legitimize the gender hierarchy existing in their national in-group (Sibley et al. 2007b). Men who reject hostile sexism may endorse benevolent sexism because it gives them advantage in access to power and status. They may be more likely to endorse benevolent sexism the more they uphold either positive belief about national identity. On the other hand, women may endorse benevolent sexism to protect the positive image of their national in-group when they are psychologically invested in this image, but reject benevolent sexism when they are not.

Like other members of disadvantaged groups who internalize beliefs that maintain inequality, women internalize benevolent sexism to protect self-esteem (Jost and Kay 2005). In order to question beliefs that legitimize inequality, members of disadvantaged groups need to maintain high self-esteem and positive beliefs about the disadvantaged in-group (Jost and Banaji 1994). Women who endorse national collective narcissism are unlikely to maintain either. Collective narcissism is an attempt to compensate for low self-esteem (Golec de Zavala et al. 2020) and frustrated expectations regarding self-importance (Golec de Zavala and Keenan 2020; Golec de Zavala et al. in press). When their self-esteem and selfimportance needs are invested in a national in-group, women may find it difficult to dissociate from this group and may be particularly motivated to adhere to its normative gender hierarchy and endorse benevolent sexism and their place in the gender hierarchy even more strongly than men.
In contrast, endorsing national in-group satisfaction may encourage women to reject benevolent sexism as a belief that legitimizes gender inequality. National in-group satisfaction is positively associated with self-esteem (Golec de Zavala et al. 2020), psychological well-being, and emotional resilience (Golec de Zavala 2019). Studies also indicate that genuine (non-compensatory, non-narcissistic) in-group pride serves as a buffer against negative consequences of being discriminated as a member of the same (Hansen and Sassenberg 2006; cf. McCoy and Major 2003) or another (McCullough et al. 2019; Yip 2009) group. By strengthening their sense of selfworth, national in-group satisfaction may motivate women to reject beliefs that justify their disadvantaged position in gender hierarchy. In addition, in-group satisfaction is associated with a need to use personal strengths toward the betterment of the in-group (Amiot and Sansfaçon 2011). Thus, women with high national in-group satisfaction may also act in support of gender equality to advance and improve their national ingroup.

\section{Overview of the Present Studies}

We test the prediction that sexism is associated with collective narcissism with reference to several social identities. We use the example of Poland, where the ultra-conservative, populist government with the support of the Polish Catholic Church propagates a narrow definition of national identity limiting national prototypicality to Catholic, heterosexual men (Graff 2010) and where gender equality may be seen as a threat to national identity (Korolczuk and Graff 2018) as defined by national collective narcissism (Golec de Zavala and Keenan 2020).

In Study 1, conducted on a nationally representative sample of Polish men, we test the prediction that male collective narcissism is associated with sexism via precarious manhood and traditional gender beliefs (sequentially, Hypothesis 1). In order to examine whether the relationship with sexism is specific to male collective narcissism, we compare it to the association between sexism and male in-group satisfaction, an alternative positive belief about gender identity that is not focused on demanding in-group's exceptionality and recognition.

In Study 2, we test the hypothesis that Catholic collective narcissism predicts tolerance of violence against women independently of religious fundamentalism and extrinsic religiosity, and with an opposite sign than intrinsic religiosity (Hypothesis 2). We test also whether the association between collective narcissism and tolerance of violence against women or any of the associations between religious orientations and tolerance of violence against women is moderated by gender. In Study 3, we test the prediction that only Polish collective narcissism is uniquely associated with hostile sexism and 
tolerance of domestic violence against women, whereas national in-group satisfaction is not associated with those variables (Hypothesis 3). Moreover, we expect that national collective narcissism is positively associated with benevolent sexism especially among women (in comparison to men, Hypothesis 4). In turn, national in-group satisfaction is negatively associated with benevolent sexism among women but positively associated with benevolent sexism among men (Hypothesis 5).

In Studies 1 and 3, we assess hostile and benevolent sexism. We use a different measure of sexism in Study 2 in order to generalize our findings beyond a specific method of measurement. In a nationally representative survey, we aske participants to what extent they agree with the belief that a husband can control and punish a wife. This measure was designed following a proposed law amendment from the Polish government's families' ministry that aimed to reclassify "single cases" [first-reported incidents] of domestic abuse as non-criminal, effectively legalizing "one-off" incidents of domestic violence against women (Rothwell 2019). In Study 3 , in addition to measures of hostile and benevolent sexism, we included another measure of acceptance of domestic violence against women also grounded in the Polish context. The measure was administered following a well-known case of domestic violence. It was perpetrated by an MP representing the ultra-conservative ruling party (Law and Justice) in Bydgoszcz against his wife. The case of prolonged physical and psychological abuse was well-documented and widely publicized (Grzyb 2019).

In all studies, we conducted the analyses including several variables indicated by previous studies as demographic predictors of sexism. In Study 1, we included education as a covariate based on research indicating that it negatively correlates with sexism (Glick et al. 2002). In Studies 2 and 3, we also added political conservatism among the covariates because religiosity is positively associated with political conservatism (Malka et al. 2012; Topidi 2019), which predicts sexism (Prusaczyk and Hodson 2018). In Study 3 , we added a measure of individual narcissism to test whether the expected association between collective narcissism and sexism is independent of the role of individual narcissism in inspiring sexism. Findings implicate individual narcissism in interpersonal violence against women (Bushman et al. 2003). Given that collective and individual narcissism positively overlap (Golec de Zavala et al. 2019), it is crucial to specify that collective, rather than individual, narcissism is independently associated with sexism.

In all of our studies, the hypothesized pattern of relationships remained the same whether covariates were entered or not. Thus, we report analyses with covariates to provide a more adequate estimate of the size of the unique association between collective narcissism and sexism.

\section{Study 1}

In Study 1, we test the hypothesis that the narcissistic belief that men as a group are exceptional but not sufficiently recognized by women predicts sexism via precarious manhood which, in turn, predicts endorsing traditional gender roles (Hypothesis 1). Thus, we expect that male collective narcissists feel uncertain about their manhood, evoke the authority of tradition to support their beliefs in traditional gender hierarchy, and endorse sexism. Additionally, we compare the hypothesized indirect association of collective narcissism with sexism to the association between sexism and gender in-group satisfaction. We expect that only collective narcissism will predict sexism via the hypothesized route.

\section{Method}

Participants Participants were 329 Polish adult men who completed the gender attitudes survey via the Ariadna Research Panel (http://www.panelariadna.com). The random-quota sample is nationally representative in terms of age and place of residence. Participants' age ranged from 18 to 79 years-old $(M=43.28, S D=15.05)$. Nine $(2.6 \%)$ participants reported basic/primary education; 31 (8.8\%), vocational education; 125 (35.6\%), secondary education; $36(10.3 \%)$, completing college degree (which, in Poland, is vocational, not a higher education degree); $31(8.8 \%)$, completing an undergraduate degree; and 119 (33.9\%), a postgraduate degree.

The present sample does not include those participants who provided a wrong response to the attention check questions ("Please choose 'I agree' as a correct answer" and "The correct answer is 'Definitely Agree," $n=32$ ). There were no significant differences with reference to any of the tested variables between participants excluded and included into the analyses.

We used the bmem package for $\mathrm{R}$ (Zhang 2014) to perform the Monte Carlo sample size estimation for chain mediation with two predictors (collective narcissism, in-group satisfaction), two sequential mediators (precarious manhood, traditional gender beliefs), and one outcome (sexism). We conservatively assumed small effect sizes for the relationship between collective narcissism and precarious manhood $\left(r_{a-}\right.$ $=.20)$. We assumed moderate effects $\left(r_{d}\right.$ and $\left.r_{b}=.30\right)$ regarding the relation between precarious manhood and traditional gender beliefs, as well as between traditional gender beliefs and sexism, because similar associations were previously documented in experimental studies (Dasgupta and Rivera 2006; Tinkler 2013; O'Connor et al. 2017; Michniewicz and Vandello 2015). We entered the effect sizes for the association between collective narcissism and prejudice derogation based on a recent meta-analysis $\left(r_{c}=.20\right.$, Golec de Zavala et al. 2019) for the links between collective narcissism and sexism. The estimation of a sample size adequate to test relationships 
of such sizes with power of .80 pointed to a sample size of 320 . W conservatively oversampled to account for missing data.

Procedure and Measures All measures listed here were presented to participants in random order, thus differently for each participant. The order of items in each of the measures was also randomized for each participant. Participants provided their response on a scale ranging from 1 (totally disagree) to 7 (totally agree). Differences in degrees of freedom in all studies are due to missing data.

Male Collective Narcissism Collective narcissism with reference to male gender identity was assessed with the five-item Collective Narcissism Scale (Golec de Zavala et al. 2009; e.g., "Men deserve special treatment"). Cronbach's alpha for the present study was .87 . This scale has previously demonstrated strong internal consistency reliability $(\alpha s=.85-.93$; Golec de Zavala, Federico et al., 2020) as well as convergent, divergent, and predictive validity (Golec de Zavala et al. 2009). We averaged items to produce an overall male collective narcissism score, where higher values denoted stronger collective narcissism.

In-Group Satisfaction In-group satisfaction was assessed with the four-item in-group satisfaction subscale of the Polish version of the In-group Identity Scale (e.g., "I am glad to be a man"; $\alpha=.84$ ). The subscale has previously demonstrated strong internal consistency in other contexts and it has been validated in previous research (Jaworska 2016; Leach et al. 2008). The Polish version of the scale was used in previous research and typically achieved very high internal consistency ( $\alpha \mathrm{s}=.93-.96$; Golec de Zavala, Federico et al., 2020). We averaged items to produce an overall in-group satisfaction score, with higher values denoting greater in-group satisfaction.

Precarious Manhood We assessed precarious manhood with the seven-item scale (Vandello et al. 2008; e.g., "It is fairly easy for a man to lose his status as a man"; $\alpha=.72$ ). The items were translated and back-translated to Polish by two independent bilingual translators. The scale has been validated and exhibited strong reliability in past research $(\alpha=.85$; Vandello et al. 2008). We created a precarious manhood mean score using all items, with higher values denoting more precarious manhood.

Traditional Gender Beliefs We measured traditional gender beliefs with seven items from the Traditional Beliefs about Gender and Gender Identity Scale pertaining to endorsement of a traditional gender hierarchy and behaviours prescribed by gender stereotypes $(\alpha=.72)$. The scale has been validated and its good internal consistency has been established in previous research (Dasgupta and Rivera 2006; $\alpha \mathrm{s}=84-.90$ ). The following items from this Scale were used: "It's important that men appear masculine and that women appear feminine"; "It is inappropriate for a man to use clear nail polish on his fingernails"; "If the aims of women's liberation are met, men will lose more than they will gain"; "A woman needs the support of a man to advance professionally"; "Children raised by single mothers are usually worse off compared to children raised by married couples"; "Men who end up gay probably didn't have strong male role models during their childhood"; and "A man who is vulnerable is a sissy." The items were chosen by experts in psychology of gender relations to pertain to traditional gender beliefs. They were translated and backtranslated to Polish by two independent bilingual translators. We averaged across items such that higher scores indicated stronger endorsement of traditional gender beliefs.

Ambivalent Sexism Ambivalent sexism was assessed with the Polish translation of hostile and benevolent sexism subscales of the 12-item version of the Ambivalent Sexism Scale. The scale has demonstrated validity and internal consistency in previous research (overall scale: $\alpha \mathrm{s}=.83-92$; subscales: .73-.92; Glick and Fiske 1996, 1997; Mikołajczak and Pietrzak 2014; Rollero et al. 2014). The six items of hostile sexism subscale tap into sexist antipathy (e.g. "Women seek to gain power by getting control over men"; $\alpha=.81$ ). The benevolent sexism subscale consists of items pertaining to viewing women stereotypically in restricted roles (e.g. "Many women have a quality of purity that few men possess"; $\alpha=.74)$. Hostile and benevolent sexism were positively correlated, $r(327)=.23, p<.001$. The predicted relationships were the same for both, benevolent, and hostile sexism. Thus, for the sake of brevity of presentation, we collapsed the subscales for the measurement of ambivalent sexism $(\alpha=.78)$. (The analyses for benevolent and hostile sexism separately can be found in the online supplement, Table $3 \mathrm{~s}$.)

Education Education was included as a covariate in our analyses. It was coded 1 (basic/primary), 2 (vocational), 3 (secondary), 4 (college), 5 (undergraduate), and 6 (postgraduate). The pattern of results was the same when educational status was not controlled for.

\section{Results}

Male collective narcissism and in-group satisfaction were positively correlated. Both were positively associated with traditional gender beliefs and sexism, but unlike collective narcissism, in-group satisfaction was not related to precarious manhood (see Table 1).

In order to test Hypothesis 1 that collective narcissism is associated with sexism indirectly via precarious manhood and traditional gender beliefs, we performed a path analysis of a 
chain mediation model with Mplus V8 (Muthén and Muthén 1998-2017). We entered precarious manhood as the first mediator, traditional gender beliefs as the second mediator, and sexism as the outcome variable. In order to test whether this indirect relationship is specific to collective narcissism in comparison to in-group satisfaction, we entered collective narcissism and in-group satisfaction as correlated predictors. We also entered education as a covariate (the analyses without this covariate yielded almost the same results). To address deviations from normal distribution of all study variables (all Kolmogorov-Smirnov $p \mathrm{~s}<.001$ ), we requested 5000 bootstrap samples and $95 \%$ bias corrected bootstrap confidence intervals.

As per $R^{2}$, the model explained $43 \%$ of variance in sexism $(S E=.05, p<.001), 32 \%$ of variance in traditional gender beliefs $(S E=.05, p<.001)$, and $5 \%$ of variance for precarious manhood $(S E=.03, p=.059)$. As predicted, the unique direct association between collective narcissism and ambivalent sexism was positive and significant $(b=.11, S E=.04,95 \% \mathrm{CI}$ $[.030 ; .18])$. Also as hypothesized, the sequential mediation via precarious manhood and traditional gender beliefs was significant $(b=.01, S E=.01,95 \%$ CI $[.001, .024])$. In line with Hypothesis 1, male collective narcissism predicted precarious manhood, which in turn predicted traditional gender beliefs which were positively associated with ambivalent sexism (see Fig. 1). The indirect effects via traditional gender beliefs $(b=.14, S E=.03,95 \%$ CI $[.090, .198])$, as well as via precarious manhood $(b=.02, S E=.01,95 \%$ CI $[.003$, .037]), were also significant.

Contrary to expectations, the unique direct association between in-group satisfaction and ambivalent sexism was positive and significant $(b=.11, S E=.04,95 \%$ CI $[.022, .187])$ (see Fig. 1). The indirect association via precarious manhood ( $b=.004, S E=.01,95 \%$ CI $[-.006, .020])$ was not significant. The indirect association referring to the chain mediation via precarious manhood and traditional gender beliefs $(b=.002$,
$S E=.004,95 \%$ CI $[-.003 ; .013])$ was not significant. However, the indirect association via traditional gender beliefs was significant $(b=.05, S E=.02,95 \%$ CI $[.014 ; .095])$. Thus, both male collective narcissism and male in-group satisfaction are independently and uniquely associated with sexism but the mechanisms underlying those associations are different.

\section{Discussion}

The results of Study 1 are in line with Hypothesis 1 . The association between male collective narcissistic and sexism is explained to a significant extent by the association between male collective narcissism and precarious manhood and traditional gender beliefs. Collective narcissism is associated with ambivalent sexism via the belief manhood is uncertain, which is associated with traditional gender beliefs, which in turn predict ambivalent sexism. The simple indirect associations via precarious manhood and traditional gender beliefs were also significant. A significant part of the association between male collective narcissism and ambivalent sexism remained unexplained by the two tested intervening variables. This suggests that the role of other social identifications as predictors of sexism should be also considered.

The present results indicate that precarious manhood mediated only the association between male collective narcissism and sexism, but not the association between male in-group satisfaction and sexism. Contrary to our prediction, male ingroup satisfaction was positively associated with ambivalent sexism independently of male collective narcissism. However, the association between in-group satisfaction and sexism was explained only by the belief in traditional gender roles but not by precarious manhood. A significant portion of the association between male in-group satisfaction and sexism remained unexplained by the tested intervening variables.

In following two studies, we tested whether collective narcissism with reference to religious and national identities is
Table 1 Descriptive statistics and correlations among variables of interest, study 1

\begin{tabular}{|c|c|c|c|c|c|c|c|c|}
\hline \multirow[b]{2}{*}{ Variables } & \multirow[b]{2}{*}{$M$} & \multirow[b]{2}{*}{$S D$} & \multicolumn{5}{|c|}{ Correlations } & \multirow[b]{2}{*}{6.} \\
\hline & & & 1. & 2. & 3. & 4. & 5. & \\
\hline 1. Collective Narcissism & 3.29 & 1.21 & - & & & & & \\
\hline 2. In-group Satisfaction & 5.34 & 1.00 & $.30^{* * * *}$ & - & & & & \\
\hline 3. Precarious Manhood & 4.21 & .90 & $.23^{* * * *}$ & .10 & - & & & \\
\hline 4. Traditional Gender Beliefs & 4.22 & .96 & $.53^{* * * *}$ & $.29^{* * * *}$ & $26^{* * *}$ & - & & \\
\hline 5. Hostile Sexism & 4.51 & 1.04 & $.48^{* * * *}$ & $.27^{* * *}$ & $.22^{* * * *}$ & $.54^{* * * *}$ & - & \\
\hline 6. Benevolent Sexism & 4.41 & 1.00 & $.26^{* * * *}$ & $.24^{* * * *}$ & $.23^{* * * *}$ & $.42^{* * * *}$ & $.23^{* * * *}$ & - \\
\hline 7. Education & - & - & $-.19^{* * * *}$ & .01 & -.09 & -.09 & -.07 & -.07 \\
\hline
\end{tabular}

Note. In all tables, Pearson's correlation coefficients are reported for the ease of interpretation. In all studies, the results of Spearman rho correlations that correct for the scales' skewed distributions yield the same pattern of results, $n=329$

$* * * p<.001$ 


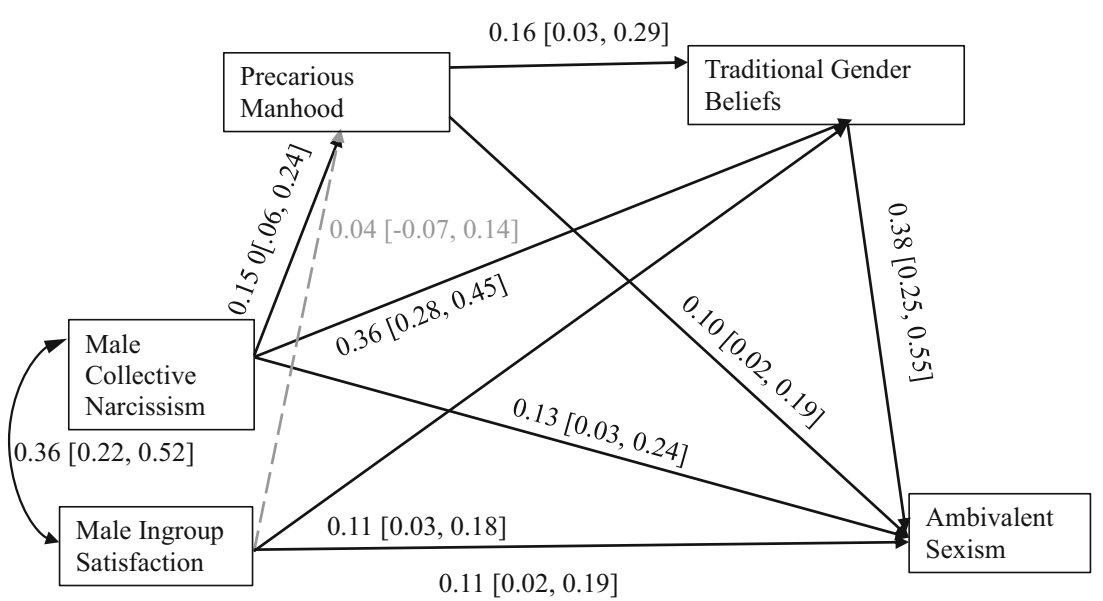

Fig. 1 Relationships among male collective narcissism, in-group satisfaction, and ambivalent sexism via precarious manhood and traditional gender beliefs. Unstandardized regression coefficients are reported. Numbers in brackets refer to lower and higher boundary of $95 \%$

also associated with sexism. Based on the literature indicating that people endorse prejudice considered normative in their groups, as well as the literature suggesting that members of disadvantaged groups may accept beliefs that justify the existing group-based hierarchies, as well as recent data suggesting that both men and women are biased against women (United Nations Development Programme 2019), we expected that collective narcissism with reference to those social identities will be associated with sexism among men and women. We compared the associations of collective narcissism to relevant competing predictors to test whether its association with sexism is unique.

\section{Study 2}

In Study 2, we examine the association between religious collective narcissism and hostile sexism, measured as tolerance of domestic violence against women, to test whether the association between collective narcissism and sexism generalizes beyond the specific measurement of ambivalent sexism. We compared the role of collective narcissism to the roles of religious fundamentalism, as well as extrinsic and intrinsic religiosity. We examined these associations in Poland where the majority reports their religion as Catholicism (Coman 2019). Thus, collective narcissism was measured with reference to a group defined as Catholics.

\section{Method}

Participants Participants were 1088 Polish adults (571 women, $52 \% ; 517$ men, 48\%), ranging in age from 18 to 83 years $(M=$ 44.31, $S D=16.20$ ). Data for Study 2 were collected by the Ariadna Research Panel as a part of a weekly opinion poll. The percentile bootstrap intervals. The dashed line denotes a nonsignificant path. The control variable education was included in the model but is not reported in the figure for the sake of simplicity

random-quota sample is nationally representative in terms of age, gender and place of residence. Participants in Study 1 could not participate in Study 2. We restricted our analyses to participants who identified their religion as Catholic because we examined Catholic collective narcissism ( $82 \%$ of the full sample). The analysed sample consisted of 891 self-identified Catholics (486 women, 55\%; 404 men, 45\%; age range from 18 to $83, M=$ 44.67, $S D=16.60)$. Women $(M=45.86, S D=17.23)$ were older than men $(M=43.25, S D=15.71 ; t(879)=5.56 ; p=.02$; $d=.34)$.

There were 228 (25.6\%) participants (113 men, 115 women) who reported basic/primary education; $201(22.5 \% ; 119$ men, 82women), a vocational education, 212 (23.8\%; 83 men, 129 women), a secondary education; 91 (10.2\%; 27 men, 64 women), completing college degree; 33 (3.7\%; 11 men, 22 women), an completing an undergraduate degree; and 126 (14.1\%; 52 men, 74 women), a postgraduate degree. Women were more educated than men, chi-square $(5)=32.27$; Cramer's V $=190 ; p<.001$.

We used the bmem package for $\mathrm{R}$ (Zhang 2014) to perform estimation of the sample size sufficient to test a regression model with 11 predictors (collective narcissism, intrinsic religiosity, extrinsic religiosity, religious fundamentalism, their interactions with gender, political conservatism, gender, and education) of hostility toward women. We conservatively assumed small effects for all relations between predictors and the outcome $(r=.20)$. Again, we chose this effect size because of the association between collective narcissism and outgroup derogation found in a recent meta-analysis $(r=.20$, Golec de Zavala et al. 2019). The estimation of a sample size adequate to test relationships of such sizes with power of .80 pointed to a sample size of 395 . We therefore concluded that our sample was sufficient to detect and compare the anticipated effects. 
Procedure and Measures Participants provided their responses on a scale ranging from 1 (totally disagree) to 6 (totally agree). The measures were presented in a separate random order for each participant. The order of items in each measure was also randomized for each participant.

Religious Collective Narcissism Collective narcissism with reference to the religious in-group was measured as in Study 1 but the items were changed to refer to Catholics (e.g., "Catholics deserve special treatment"; $\alpha=.95)$. Previous research used this scale with slightly different wording (using "The Catholic Church" instead of "Catholics") and found comparable reliability ( $\alpha=.93$; Marchlewska et al. 2019). We averaged items to produce an overall religious collective narcissism score, where greater values denoted higher collective narcissism.

Religious Fundamentalism We assessed religious fundamentalism with the 12-item scale proposed by Altemeyer and Hunsberger (2004). The items pertain to the belief in only one set of religious teachings that contains the fundamental, inerrant truth about humanity and its deity which must be followed according to immutable past practice (e.g. "God has given humanity a complete, unfailing guide to happiness and salvation, which must be totally followed"; $\alpha=.91$ ). The scale has exhibited validity and strong reliability in the past $(\alpha=.92$; Altemeyer and Hunsberger 2004). We averaged items to form an overall religious fundamentalism score, where greater values denoted higher religious fundamentalism.

Intrinsic and Extrinsic Religious Orientations We measured intrinsic and extrinsic religious orientations by means of the respective scales revised by Francis and colleagues (Francis 2007; Francis et al. 2016; see also Batson et al. 1993) based on validated and reliable scales presented by Gorsuch and McPherson (1989). The six items assessing intrinsic religiosity pertain to an intrinsic motivation to engage in religious activities, such as prayer or attendance in service (e.g., "I pray at home because it helps me be aware of God's presence"; $\alpha=.91)$. The six items assessing extrinsic religiosity pertain to an extrinsic motivation and external incentives to religious activities (e.g. "I go to church because it helps me to feel part of a community"; $\alpha=$.96). Francis (2007) found good internal consistency (intrinsic: $\alpha=.89$; extrinsic: $\alpha=.81$ ), as well as satisfactory concurrent validity for both subscales. We averaged items to form separate intrinsic and extrinsic religious orientation scores, where higher values denoted stronger intrinsic and extrinsic religious orientation.

Tolerance of Violence against Women In consultation with four experts in psychology and social anthropology we created three items: "A husband can sometimes hit his wife to teach her a lesson," "A husband can demand that his wife uses or does not use contraception," and "A wife should seek her husband's approval of people she associates with" $(\alpha=.80)$. We averaged items to form an overall tolerance of violence against women score, where greater values denoted higher tolerance of violence against women.

Political Conservatism We assessed political conservatism with one item offering five response options ranging from 1 (conservative), 2 (rather conservative), 3 (difficult to say, a bit conservative, a bit liberal), 4 (rather liberal) and 5 (liberal). The scale was reversed scored so that a higher score reflects higher political conservatism.

Demographics Gender was coded 0 (male) and 1 (female). As in Study 1, we included education as a covariate, coded 1 (primary), 2 (vocational), 3 (secondary), and 4 (higher). The pattern of results was the same regardless of whether the covariates were entered or not.

\section{Results}

Among both men and women, all variables pertaining to religious identification were positively correlated with each other (see Table 2). Only those variables, but not self-reported political conservatism, were positively associated with tolerance of violence against women. Interestingly, political conservatism was positively associated with collective narcissism and all three forms of religious identification only among women but not among men. Tolerance of violence against women and religious fundamentalism were higher among men than women.

We applied Templeton's (2011) two stage normalization procedure prior to the analyses testing the hypotheses because the distribution of tolerance of violence toward women was skewed. This procedure significantly reduced skewness (from skewness $=1.38, S E=.08$, to skewness $=.53, S E=.08)$ without achieving normal distribution (Kolmogorov-Smirnov $D(877)=.21, p<.001)$. Therefore, we additionally used non-parametric bootstrap (Davison and Hinkley 1997) to account for non-normality.

In order to test Hypothesis 2 that Catholic collective narcissism predicts sexism independently of religious fundamentalism and extrinsic religiosity and with an opposite sign than intrinsic religiosity, we performed a multiple regression analysis in the R package car (Fox and Weisberg 2019). We entered tolerance of violence against women as the outcome variable. In Model 1, we entered the demographic variables: political conservatism, education, and gender. In Model 2, we entered religious fundamentalism and intrinsic and extrinsic religious orientation as independent predictors. In Model 3, we added collective narcissism. In order to test the boundary conditions for the relationships of the predictors with the outcome variable, in Model 4, we entered their moderation by gender. Again, to account for the non-normal distribution of 
Table 2 Descriptive statistics and correlations among variables of interest among men and women, study 2

\begin{tabular}{|c|c|c|c|c|c|c|c|c|c|c|c|c|c|}
\hline & & \multirow{2}{*}{$\begin{array}{l}\text { Women } \\
M(S D)\end{array}$} & \multirow{2}{*}{$\begin{array}{l}\text { Men } \\
M(S D)\end{array}$} & \multirow[b]{2}{*}{$t$} & \multirow[b]{2}{*}{$p$} & \multirow[b]{2}{*}{$d$} & \multicolumn{6}{|c|}{ Correlations } & \multirow[b]{2}{*}{7} \\
\hline & & & & & & & 1 & 2 & 3 & 4 & 5 & 6 & \\
\hline 1 & Tolerance for Violence & $1.54(1.01)$ & 2.43(.89) & 13.79 & $<.001$ & .84 & - & $.29^{* * *}$ & $.19^{* * *}$ & $.25^{* * *}$ & $.27^{* * * *}$ & .10 & $-.18^{* * * * *}$ \\
\hline 2 & Collective Narcissism & $2.84(1.41)$ & $3.07(1.24)$ & 2.58 & .01 & 0.17 & $.51^{* * * *}$ & - & $.64^{* * * *}$ & $.73^{* * * *}$ & $.69^{* * * *}$ & .08 & -.10 \\
\hline 3 & Intrinsic Religiosity & $3.63(1.36)$ & $3.76(1.06)$ & 1.53 & .13 & 0.10 & $.36^{* * * *}$ & $.73^{* * * *}$ & - & $.69^{* * * *}$ & $.80^{* * * *}$ & .09 & -.08 \\
\hline 4 & Extrinsic Religiosity & $3.17(1.50)$ & $3.23(1.23)$ & .62 & .54 & .04 & $.43^{* * * *}$ & $.80^{* * * *}$ & $.84^{* * * *}$ & - & $.64^{* * * *}$ & .02 & .01 \\
\hline 5 & Religious Fundamentalism & $3.25(1.36)$ & $3.61(1.17)$ & 4.20 & $<.001$ & .28 & $.47^{* * * *}$ & $.80^{* * * *}$ & $.87^{* * * *}$ & $.86^{* * *}$ & - & .09 & $-.18^{* * * *}$ \\
\hline 6 & Political Conservatism & $3.15(.82)$ & $2.97(.86)$ & -3.15 & .002 & .21 & -.02 & $.26^{* * * *}$ & $.29^{* * * *}$ & $.26^{* * * *}$ & $.24^{* * * *}$ & - & .04 \\
\hline 7 & Education & - & - & - & - & - & -.06 & $.15^{* * * *}$ & $.10^{*}$ & $.09^{*}$ & $.12^{* *}$ & $-.20^{* * * *}$ & - \\
\hline
\end{tabular}

Note. $n=891\left(n_{\mathrm{women}}=486 ; n_{\mathrm{men}}=405\right)$. Correlations for women are presented below, and correlations for men above, the diagonal of the correlation matrix

$* p<.05 . * * p<.01 . * * * p<.001$

the outcome variable, we used 5000 bootstrap samples and bias-corrected accelerated bootstrap confidence intervals. Despite high correlations between study variables, we did not find multicollinearity $(1.02<\mathrm{VIF}<3.70)$. Additionally, we performed dominance analyses to test the same hypothesis using an alternative method (see the online supplement, Table 4s).

Model 1 was significant, explaining $21 \%$ of variance in tolerance of domestic violence against women as per adjusted $R^{2}$. Model 2 was also significant and significantly better than Model 1, explaining additional $10 \%$ of variance in the outcome variable. Model 3 was also significant and significantly better than Model 2, explaining additional 2\% of variance in the outcome variable. This finding is in line with our expectation that collective narcissism predicts tolerance of violence against women independently of religious fundamentalism, which predicted it positively, and intrinsic religiosity (as well as education and female gender), which predicted it negatively. Extrinsic religiosity and political conservatism did not make unique predictions of tolerance of violence against women. None of the interactions with gender tested in Model 4 was significant (see Table 3). Thus, the unique associations among collective narcissism, religious fundamentalism, and intrinsic religiosity with tolerance of violence against women did not differ among women and men.

\section{Discussion}

Results of Study 2 indicate that neither men nor women in Poland accept domestic violence against women, but women accept it significantly less than men. The results of Study 2 are also in line with Hypothesis 2. Across gender groups, Catholic collective narcissism predicts tolerance of domestic violence toward women independently of religious fundamentalism and extrinsic religiosity (the latter is unrelated to tolerance of violence against women after other variables are considered, similarly to political conservatism). Intrinsic religiosity is negatively related to tolerance of violence against women. Gender does not moderate the associations among Catholic collective narcissism, religious orientations and tolerance of violence against women. This means that men and women tolerate violence against women when they endorse Catholic collective narcissism. In the next study, we compare the association between national collective narcissism and sexism (benevolent and hostile) and tolerance of domestic violence against women to the association between national in-group satisfaction with sexism among men and women.

\section{Study 3}

In Study 3, we test Hypothesis 3 that only national collective narcissism (but not national in-group satisfaction) is associated with hostile sexism and tolerance of violence against women. In addition, we test Hypothesis 4, that the positive association between national collective narcissism and benevolent sexism may be stronger among women than among men, and Hypothesis 5 that the association between national in-group satisfaction and benevolent sexism may be negative among women but positive among men. Finally, we tested whether the role of collective narcissism in explaining sexism is specific and unique in comparison to individual narcissism.

\section{Method}

Participants Data for Study 3 were collected by the Ariadna Research Panel as a part of a weekly opinion poll. The random-quota sample is nationally representative in terms of age, gender, and place of residence. Participants in Studies 1 and 2 could not participate in Study 3. The sample consisted of 1070 Polish adults (570 women, 53\%, 500 men, 47\%), 
Table 3 Multiple hierarchical regression for tolerance for violence against women as the outcome and gender as a moderator of the relationships between collective Narcissism's and religious orientations' associations with tolerance of violence against women in study 2

\begin{tabular}{|c|c|c|c|c|c|c|c|c|c|c|c|c|}
\hline & \multicolumn{3}{|l|}{ Step 1} & \multicolumn{3}{|l|}{ Step 2} & \multicolumn{3}{|l|}{ Step 3} & \multicolumn{3}{|l|}{ Step 4} \\
\hline & $b$ & $S E_{b}$ & $95 \% \mathrm{CI}$ & $b$ & $S E_{b}$ & $95 \% \mathrm{CI}$ & $b$ & $S E_{b}$ & $95 \% \mathrm{CI}$ & $b$ & $S E_{b}$ & $95 \% \mathrm{CI}$ \\
\hline Intercept & 2.35 & 0.15 & {$[2.05,2.65]$} & 1.96 & 0.15 & {$[1.68,2.25]$} & 2.02 & 0.15 & {$[1.73,2.3]$} & 2.09 & .19 & {$[1.71,2.46]$} \\
\hline Political Conservatism (PC) & .13 & .03 & {$[.07, .18]$} & .01 & .03 & {$[-.05, .07]$} & -.02 & .03 & {$[-.08, .04]$} & .00 & .04 & {$[-.09, .08]$} \\
\hline Education & -0.12 & .04 & {$[-.19,-.04]$} & -0.10 & .04 & {$[-0.17,-.03]$} & -0.10 & .04 & {$[-0.17,-.03]$} & -0.10 & .04 & {$[-0.17,-.03]$} \\
\hline Gender & -.75 & .05 & {$[-.85,-.64]$} & -.74 & .05 & {$[-.84,-.64]$} & -.74 & .05 & {$[-.83,-.64]$} & -.85 & .19 & {$[-1.23,-.47]$} \\
\hline Intrinsic Religiosity (INR) & & & & -0.11 & .03 & {$[-.18,-.05]$} & -.12 & .03 & {$[-.18,-.05]$} & 0.17 & .05 & {$[.07, .26]$} \\
\hline Extrinsic Religiosity (EXR) & & & & .13 & .03 & {$[.07, .19]$} & .05 & .03 & {$[-.01, .12]$} & -.14 & .05 & {$[-.25,-.04]$} \\
\hline Religious Fundamentalism (RF) & & & & .20 & .03 & {$[.13, .27]$} & 0.15 & .04 & {$[.07, .22]$} & .04 & .05 & {$[-.06,0.15]$} \\
\hline Collective Narcissism (CN) & & & & & & & .16 & .03 & {$[0.10, .22]$} & .14 & .06 & {$[.04, .26]$} \\
\hline Gender X CN & & & & & & & & & & -.02 & .06 & {$[-.14,0.11]$} \\
\hline Gender X INR & & & & & & & & & & .05 & .07 & {$[-.08, .18]$} \\
\hline Gender X EXR & & & & & & & & & & .02 & .07 & {$[-0.12, .14]$} \\
\hline Gender X RF & & & & & & & & & & .00 & .07 & {$[-.14, .14]$} \\
\hline$F$ & 78.68 & & & 67.13 & & & 62.83 & & & 36.64 & & \\
\hline$d f$ & 3 & & & 6 & & & 7 & & & 12 & & \\
\hline$d f_{\text {error }}$ & 873 & & & 870 & & & 869 & & & 865 & & \\
\hline$p_{F}$ & $<.001$ & & & $<.001$ & & & $<.001$ & & & $<.001$ & & \\
\hline$R_{\text {adj }}^{2}$ & .21 & & & .31 & & & .33 & & & .33 & & \\
\hline$\Delta R_{\text {adj }}^{2}$ & & & & .10 & & & .02 & & & .00 & & \\
\hline$p_{\Delta R}{ }^{2}$ adj & & & & $<.001$ & & & $<.001$ & & & .90 & & \\
\hline
\end{tabular}

Note. $n=891\left(n_{\text {women }}=486 ; n_{\text {men }}=405\right)$. Unstandardized regression coefficients are reported. $95 \%$ CI refers to $95 \%$ bias-corrected accelerated confidence intervals estimated with 10,000 bootstrap samples

ranging in age from 18 to 95 years-old $(M=44.15, S D=$ 15.60). There was no significant difference in age between women $(M=44.39, S D=15.14)$ and men $(M=43.41, S D=$ 15.74), $t(1016)=1.02, p=.31, d=.06)$.

Thirty six (3.6\%; 22 men, 14 women) participants reported basic/primary education; 168 (16.9\%; 109 men, 67 women), vocational education; 374 (36.7\%; 175 men, 199 women), secondary education; 131 (12.9\%; 51 men, 80 women), completing a college degree, 78 (7.7\%; 37 men, 41 women), completing an undergraduate degree; and 230 (22.6\%; 97 men, 133 women), a postgraduate degree. Women were more educated than men, $\chi^{2}$ (5) $=20.42, p<.001$, Cramer's $V=142$. Differences in degrees of freedom are due to missing data. We estimated sample size necessary to test our hypotheses with a power of .80. We used Monte Carlo data simulation in the $\mathrm{R}$ package bmem (Zhang 2014). First, we estimated the sample size for a multiple regression model with one predictor (gender), two independent moderators (collective narcissism, in-group satisfaction), and two interaction terms. In this model, we assumed an effect $r=.20$ for each of the variables and interaction terms; first, because we considered it the smallest effect of theoretical relevance and second, because a similar correlation was found between collective narcissism and out-group attitudes in a recent meta-analysis
(Golec de Zavala et al. 2019). The analysis showed that 200 participants would be needed to detect such effects.

Then, we estimated power for a multiple regression model with one predictor (gender), four independent moderators (collective narcissism, in-group satisfaction, individual narcissism, political conservatism), one control variable, and five interaction terms. This time we assumed an effect $r=.20$ for each of the variables and $r=.15$ for each of the interaction terms for a more conservative test of the unique contribution of collective narcissism. The analysis showed that 350 participants would be needed to detect such effects with a power of .80. These analyses do not address the technical multicollinearity found in moderation models that may slightly reduce actual statistical power (Aguinis 1995). Thus, we concluded that using a larger sample size would be reasonable.

Procedure and Measures Unless otherwise indicated, participants completed all measures on a scale ranging from 1 (totally disagree) to 7 (totally agree). The measures were presented in a separate random order for each participant. The order of items within measures was also randomized for each participant. 
National Collective Narcissism We measured national collective narcissism with a five-item Collective Narcissism Scale used with reference to a national in-group (Golec de Zavala et al. 2009, 2020; e.g., "Poland deserves special treatment"; $\alpha=.92)$. We averaged items to produce an overall national collective narcissism score, where greater values denoted higher collective narcissism.

National in-Group Satisfaction In-group satisfaction was assessed with the four-item in-group satisfaction subscale of the Polish version of the In-group Identity Scale (Jaworska 2016; Leach et al. 2008; e.g., "I am glad to be Polish": $\alpha=.94)$. We averaged items to produce an overall national in-group satisfaction score, where greater values denoted higher in-group satisfaction.

Hostile and benevolent sexism were assessed as in Study 1 (hostile: $\alpha=.80$; benevolent: $\alpha=.83$; ambivalent: $\alpha=.83$ ).

Tolerance of violence against women was assessed by one item asking participants' opinion about a real-life case of domestic violence. The item read:

The former MP from the Law and Justice in Bydgoszcz, physically abused and humiliated his wife. The prosecutor demanded a sentence of $30 \mathrm{~h}$ of community service monthly. This punishment is too lenient for prolonged domestic violence. To what extent do you agree with this opinion?

The item was recoded so the higher the score, the higher the acceptance of violence against women.

Individual Narcissism We assessed individual narcissism with a Polish translation of the 16-item Narcissistic Personality Inventory (Ames et al. 2006), which was used in previous research (Golec de Zavala et al. 2016). In previous research the scale demonstrated acceptable internal consistency ( $\alpha=.72$ ) as well as convergent, discriminant, and predictive validity (Ames et al. 2006). Participants were asked to choose between pairs of statements. The pairs contain one narcissistic (e.g., "I like to be the center of attention") and one nonnarcissistic (e.g., "I prefer to blend in with the crowd") statement. Narcissistic choices are scored as 1, non-narcissistic as 0 . Scores are then summed to form a narcissism index $(\alpha=.72)$. Higher scores indicate stronger individual narcissism.

Political Conservatism We assessed political conservatism with one item offering five response options ranging from 1 (conservative), 2 (rather conservative), 3 (difficult to say, a bit conservative, a bit liberal), 4 (rather liberal) and 5 (liberal). The scale was reversed scored so that a higher score reflects higher political conservatism.

Demographics Gender was coded 0 (male) and 1 (female). As in previous studies, we included education as a covariate, coded 1 (primary), 2 (vocational), 3 (secondary), and 4 (higher). The pattern of results was the same regardless of whether this covariate was entered or not.

\section{Results}

Among men and women, collective narcissism and political conservatism were positively correlated with tolerance of violence against women (see Table 4). Additionally, individual narcissism was positively associated with tolerance of violence against women only among men. Collective narcissism, in-group satisfaction, and political conservatism were positively associated with both forms of sexism. Women scored higher on the scale of benevolent sexism and in-group satisfaction, whereas men scored higher on the scale of hostile sexism and political conservatism. There were no gender differences in tolerance of violence against women. The latter was low among both genders, below the midpoint of the scale, replicating the results from Study 2 .

In order to test Hypotheses 3, 4 and 5, we performed a moderated path analysis using Mplus V8 (Muthén and Muthén 1998-2017). We entered benevolent sexism, hostile sexism, and tolerance of violence against women as correlated outcome variables. We entered collective narcissism and national in-group satisfaction as correlated predictors. We entered political conservatism, education, and individual narcissism as covariates. We used the multigroup approach to simultaneously estimate the same model for two groups: men and women. To test for moderation, we estimated contrasts by subtracting the effects of these predictors among women from the effects among men, so that a positive value indicated a stronger effect among men and a negative value indicated a stronger effect among women. This approach does not depend on the assumption of equal variances, and the parameter estimates and statistical inferences are not affected by this assumption being satisfied (Ryu and Cheong 2017). Otherwise, testing the statistical significance of the difference in path coefficients (i.e., the contrast) is identical as testing the significance of a dummy-coded variable - testing the effect at value 1 (i.e., women) of the moderator against the effect at 0 (i.e., men) (Hayes 2017).

To account for the non-normal distribution of the outcome variables (Kolmogorov-Smirnov $D(1070)=.10, p<.001)$, we used bootstrapping with 5000 samples and bias-corrected accelerated confidence intervals. Because tolerance of violence measure's distribution was skewed, prior to the analysis we additionally applied Templeton's (2011) two stage normalization procedure to this variable. This procedure significantly reduced skewness (from skewness $=1.74, S E=.08$ to skewness $=1.02, S E=.08)$ without achieving normal distribution (Kolmogorov-Smirnov $D(1070)=.39, p<.001)$.

First, in order to test Hypothesis 3 that national collective narcissism, but not national in-group satisfaction, is associated with hostile sexism and tolerance of violence against women, 
Table 4 Descriptive statistics and correlations among variables of interest among men and women, study 3

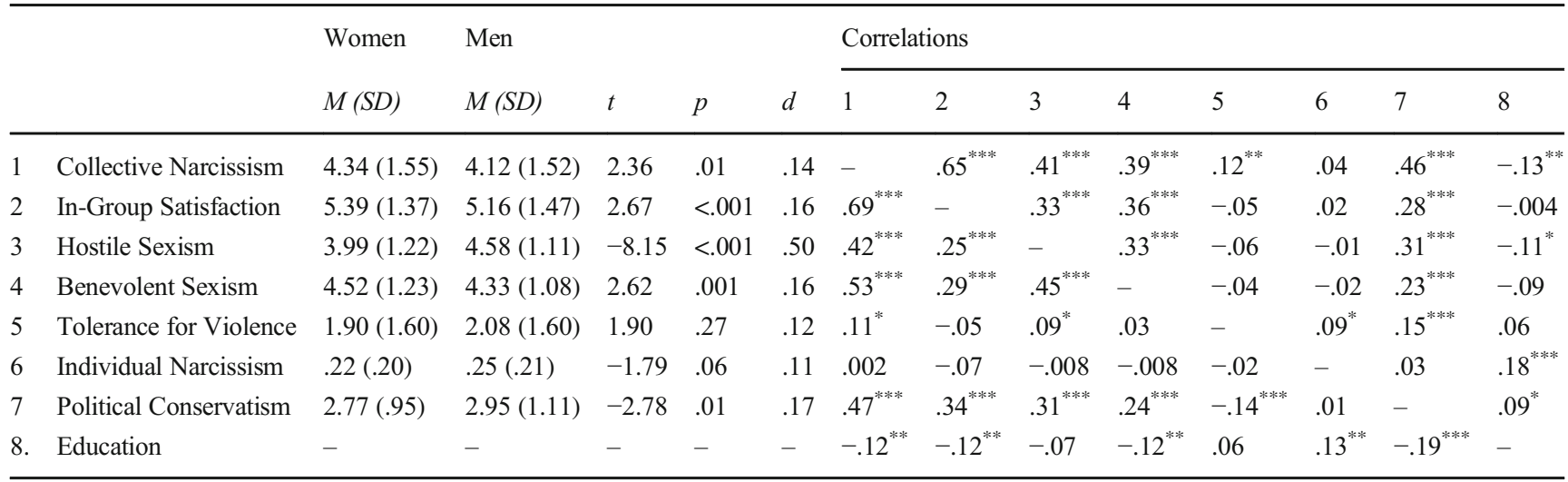

Note. $n=1070\left(\mathrm{n}_{\mathrm{women}}=568 ; \mathrm{n}_{\mathrm{men}}=502\right)$. Correlations for women are presented below, and correlations for men above, the diagonal of the correlation matrix

$* p<.05 . * * p<.01 . * * * p<.001$

we looked at independent associations of both predictors with outcome variables across gender. As per adjusted $R^{2}$, across both gender groups, the model explained $13 \%$ of variance in hostile sexism $(S E=.02, p<.001)$ and $7 \%$ of variance in tolerance of violence against women $(S E=.01, p<.001)$. The analyses indicate that national collective narcissism is, as predicted by Hypothesis 3, positively associated with hostile sexism $(b=.23, S E=.04,95 \%$ CI $[.156, .306])$ and tolerance of violence against women $(b=.20, S E=.03,95 \%$ CI [.135, .264]). As predicted by Hypothesis 3, national in-group satisfaction is not associated with hostile sexism $(b=-.002$, $S E=.04,95 \%$ CI $[-.078, .075])$. Contrary to Hypothesis 3 , national in-group satisfaction is significantly associated with rejection of violence against women $(b=-.24, S E=.03,95 \%$ CI $[-.301,-.169])$. These results did not differ significantly between genders (contrasts for men: $b=.14, S E=.07,95 \% \mathrm{CI}$ $[-.272, .001]$; for women: $b=-.01, S E=.07,95 \%$ CI [-.140, .118). The results are in line with Hypothesis 3 and additionally show that national in-group satisfaction predicts rejection of violence against women across genders (rather than has no unique association with this variable; contrast: $b=.06$, $S E=.07,95 \%$ CI $[-.075, .195])$.

Next, in order to test Hypothesis 4 that national collective narcissism is associated with benevolent sexism more strongly among women in comparison to men and Hypothesis 5 that national in-group satisfaction is associated negatively with benevolent sexism among women and positively associated with benevolent sexism among men, we looked at independent associations of national collective narcissism and ingroup satisfaction with benevolent sexism separately for men and for women. To test for gender moderation expected by Hypotheses 4 and 5, we estimated contrasts by subtracting the unique association effects of both predictors among women from the effects among men.
Across genders, national collective narcissism was positively associated with benevolent sexism $(b=.34, S E=.04$, $95 \%$ CI $[.274, .413])$, whereas national in-group satisfaction was not related to benevolent sexism $(b=.01, S E=.04,95 \%$ CI $[-.062, .078])$. The analyses performed among women show that national collective narcissism and national ingroup satisfaction explained $30 \%$ of variance in benevolent sexism $(S E=.04, p<.001)$. Among men, the predictors explained $16 \%$ of variance in benevolent sexism $(S E=.04$, $p<.001)$.

The analyses to test Hypothesis 4 indicate that among women and men, national collective narcissism is positively and significantly associated with benevolent sexism (see Fig. 2). This association is, as predicted by Hypothesis 4, significantly stronger among women than among men (contrast: $b=-.33, S E=.07,95 \% \mathrm{CI}[-.471,-.196])$. The analyses to test Hypothesis 5 show that, as predicted by Hypothesis 5 , national in-group satisfaction is negatively and significantly associated with benevolent sexism among women, as well as positively and significantly associated with benevolent sexism among men (see Fig. 2). This association is, as predicted, significantly different among men and women (contrast: $b=.28, S E=.07,95 \%$ CI $[.145, .481])$.

In addition, among women, national in-group satisfaction was negatively associated with hostile sexism. Among men this association was positive (see Fig. 2). Both associations were not significant but the difference between men and women with respect to this association was significant (contrast: $b=.17, S E=.07,95 \%$ CI $[.022, .306])$.

Finally, with respect to the question of whether collective narcissism is a unique predictor of sexism in comparison to individual narcissism, the analyses indicate that collective narcissism explains a significant portion of variance in all indices of sexism over and above individual narcissism. The latter is 
Fig. 2 Relationships among national collective narcissism, ingroup satisfaction and three facets of sexism in the group of men $\left({ }^{\mathrm{M}}\right)$ and women $\left({ }^{\mathrm{W}}\right)$. Unstandardized regression coefficients are reported. Numbers in brackets refer to lower and higher boundary of 95\% percentile bootstrap intervals. The dashed line denotes the non-significant path. Control variables education, conservatism, and individual narcissism were included in the model but are not reported in the figure for the sake of simplicity

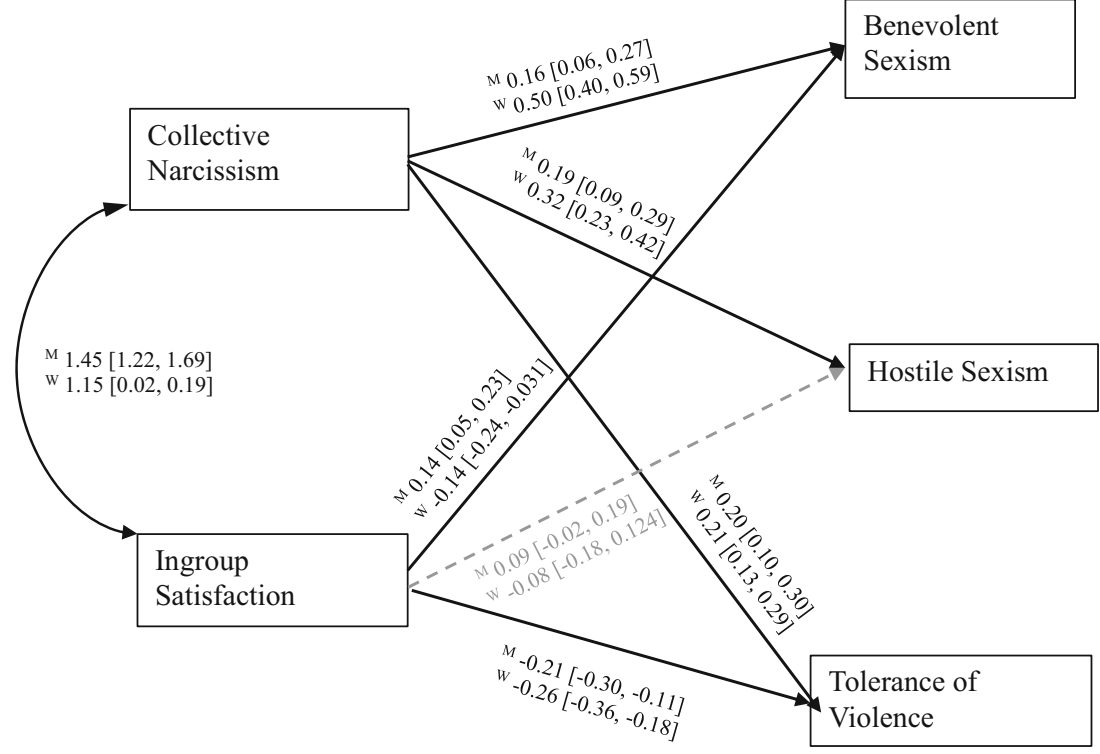

not associated with any of those indices. Analyses without covariates produced the same pattern of results as analyses including covariates. These results indicate that collective narcissism uniquely predicts sexism and tolerance of violence against women whereas individual narcissism does not uniquely contribute to explaining those variables.

\section{Discussion}

The results of Study 3 corroborate the findings of Study 2 indicating that neither men nor women accept specific instances of violence against women. Women are less tolerant than men of hostile sexism, but they are more likely than men to accept benevolent sexism. Those results are in line with findings indicating that women internalize benevolent sexism (Sibley et al. 2007a, b, 2009). In line with Hypothesis 3, the results of Study 3 indicate that across genders, national collective narcissism is a unique predictor of all forms of sexism in comparison to national in-group satisfaction. The latter is not associated with benevolent or hostile sexism and, contrary to expectations, it is negatively associated with acceptance of violence against women. The present results indicate that the associations among national collective narcissism, national ingroup satisfaction, and benevolent and hostile sexism are moderated by gender. In line with Hypothesis 4, national collective narcissism is associated with benevolent sexism more strongly among women in comparison to men. In line with Hypothesis 5, national in-group satisfaction is negatively associated with benevolent sexism among women but positively associated with benevolent sexism among men. In addition, contrary to expectations, the same significant pattern of between gender differences concerns the association between national in-group satisfaction and hostile sexism. Although this association was not significant in either group, it had a positive sign among men and a negative sign among women and the difference between genders was statistically significant. In addition, the results of Study 3 show that collective, but not individual, narcissism predicts sexisms.

\section{General Discussion}

The present results converge to indicate that sexism is embedded in several social identities provided that their content is defined by collective narcissism: a belief that the in-group is exceptional but not sufficiently recognized by others (Golec de Zavala et al. 2009, 2019). Male, religious (Catholic), and national collective narcissism in Poland were associated with sexism across different methods of its measurement. Male collective narcissism predicted hostile and benevolent sexism. Religious collective narcissism predicted tolerance of domestic violence against women, over and above religious fundamentalism. National collective narcissism predicted hostile and benevolent sexism as well as acceptance of lenient punishment for domestic violence against women.

These associations were significant after the known covariates of sexism such as education or political conservatism were taken into account. They were also significant after ingroup satisfaction, religious orientations (religious fundamentalism; intrinsic and extrinsic religiosity), and individual narcissism were taken into account. Thus, they were specific to collective narcissism independently of those variables. Those results suggest that although individual narcissism is often implicated in interpersonal violence against women (Bushman et al. 2003; Zeigler-Hill et al. 2013), collective narcissism is implicated in sexism, an attitude toward women as a social group. These results are in line with previous findings that collective rather than individual narcissism is 
associated with prejudice and hostility toward out-groups (Golec de Zavala et al. 2009, 2019; Golec de Zavala and Lantos 2020).

Thus, the present results corroborate and extend previous findings that collective narcissism is related to intergroup hostility (Golec de Zavala et al. 2019). They are also in line with previous findings that national collective narcissism predicts prejudice toward underprivileged national subgroups (Golec de Zavala et al. 2013a, 2020; Lyons et al. 2010). Moreover, they indicate that there are other forms of positive beliefs about national and religious (but not gender) groups that are not related to sexism.

\section{Male Collective Narcissism and Sexism}

Male collective narcissism was associated with sexism via a sequential mediation of precarious manhood and traditional gender beliefs that predicted hostile and benevolent sexism. Thus, collective narcissism among men was associated with uncertainty regarding their social status related to an attempt to ground it in traditional gender beliefs promoting male dominance over women. Those results go beyond previous findings linking precarious manhood to various attempts to buttress stereotypical masculinity and harass women (Bosson and Vandello 2013; Vandello et al. 2008). They indicate that the more they feel uncertain about their status men may seek to stabilize it by adhering to beliefs that justify existing gender inequalities.

The present results extend and complement previous findings indicating that male collective narcissism is negatively related to men's solidarity with women's collective actions against gender discrimination (Górska et al. 2019). The present results elucidate that male collective narcissism is associated with sexism and endorsement of gender inequality when men feel their masculinity is threatened. More generally, the present results are also in line with previous findings indicating that collective narcissism is associated with intergroup hostility because of the perception of the in-group as continuously threatened (Dyduch-Hazar et al. 2019; Golec de Zavala and Cichocka 2012; Golec de Zavala et al. 2019). They align with the understanding of collective narcissistic hostility as subjectively defensive. They also suggest that collective narcissists defended group-based privilege (Golec de Zavala and Keenan 2020; Golec de Zavala et al. in press). This suggests that the more women seek emancipation, the more this may trigger hostility and resistance of collectively narcissistic men who are uncertain of their status.

Men who are satisfied and proud of their gender identity, but not narcissistic about it, still endorse sexism. The association between male in-group satisfaction and sexism is independent of the association between male collective narcissism and sexism. It is explained, to some extent, by the association between male in-group satisfaction and traditional gender beliefs. This indirect positive association between in-group satisfaction and sexism is in contrast with previous findings comparing the intergroup consequences of collective narcissism and in-group satisfaction in the context of other social identities. Those results typically indicate that once the positive overlap between collective narcissism and in-group satisfaction is partialled out, non-narcissistic in-group satisfaction is associated with tolerance toward out-groups (Golec de Zavala 2011; Golec de Zavala et al. 2019) and with beliefs that mitigate intergroup hostility (Dyduch-Hazar et al. 2019). The present results suggest that this tendency does not extend to the relationship between male in-group satisfaction and sexism. This finding suggests that sexism may be particularly persistent form of prejudice and gender equality particularly difficult to achieve. The present results suggest that positive beliefs about male gender identity are related to sexism especially in social contexts that encourage traditional gender beliefs-like Poland, where traditional gender beliefs are linked to religious and national identity.

\section{Religious Collective Narcissism and Sexism}

In Poland the collective narcissistic claim to national exceptionality is based on the nation's attachment to traditional Catholicism. Thus, the definition of national identity is closely linked to the teachings of the Catholic Church regarding the normative gender hierarchy (Golec de Zavala et al. in press; Korolczuk and Graff 2018; Mole et al. 2020; Topidi 2019). The gender hierarchy supported by the teachings of the Catholic Church creates a normative climate in which sexism seems appropriate to both men and women. However, the present results indicate that not all forms of religious and national identity are associated with hostility toward women. Some beliefs about those social identities may serve as a platform to reject sexism among men and women. Although religious collective narcissism and religious fundamentalism are associated with acceptance of domestic violence toward women with almost equal strength, intrinsic religious orientation is associated with opposition to domestic violence against women.

Such results are in line with previous findings indicating that religious fundamentalism is positively, whereas intrinsic religiosity is negatively, associated with prejudice (Altemeyer and Hunsberger 2004; Batson et al. 1986). They extend the previous findings linking Catholic religious identification to sexism (Glick et al. 2002; Mikołajczak and Pietrzak 2014, 2015) by clarifying that it is religious collective narcissism, rather than other forms of approaching religion as social identity (e.g. extrinsic religiosity), that is associated with hostile sexism.

The present results may also help to clarify the inconsistent findings suggesting that intrinsic religious orientation is not related to racial prejudice (Batson et al. 1986) and hostile 
sexism (Burn and Busso 2005), but is associated with sexual prejudice (Herek 1987). They suggest that such findings may be explained by the positive overlap between intrinsic religiosity and religious collective narcissism that was unaccounted for by previous studies. The present results clarify that when this overlap is partialled out, intrinsic religiosity is associated with rejection of violence against women. This qualified association is in contrast to the positive zero-order correlation between intrinsic religiosity and tolerance of violence against women. This pattern suggests that the positive overlap between religious collective narcissism and intrinsic religiosity suppresses the negative association between intrinsic religiosity and tolerance of violence against women. Thus, the present results suggest that emphasizing Catholic religious teachings that prescribe equality may be used to reduce hostile sexism among men and women. This conclusion is in line with previous findings that the positive overlap between collective narcissism and non-narcissistic positive beliefs about ingroups supresses the negative associations of the latter with prejudice (Golec de Zavala 2011).

\section{National Collective Narcissism, National in-Group Satisfaction, and Sexism}

The present results extend previous findings that national collective narcissism and national in-group satisfaction have opposite unique associations with intergroup hostility (Golec de Zavala et al. 2020) and prejudice toward national minorities (Mole et al. 2020). Whereas collective narcissism is associated positively with intergroup hostility and prejudice, national ingroup satisfaction is either not associated or associated negatively. The present results indicate that national collective narcissism is consistently associated with sexism (benevolent and hostile) and tolerance of domestic violence against women, whereas national in-group satisfaction is not associated with hostile sexism and predicts rejection of violence against women. This pattern suggests that sexism may seem normative only to those Poles who hold a collectively narcissistic belief about their national identity. This seems to pertain to those Poles who support the current ultraconservative government (Golec de Zavala and Keenan 2020). In line with those findings, the results of Study 3 (presented in the online supplement) indicate that national collective narcissism, national ingroup satisfaction, as well as benevolent and hostile sexism were higher among participants who declared intention to vote for the conservative ruling Prawo i Sprawiedliwosc than participants who declared intention to vote for centrist and leftist parties. This may explain why some Polish men and women publicly and passionately express sexist beliefs that undermine women and maintain gender-based hierarchy (Davies 2016).

Moreover, the present results indicate that among women, national collective narcissism is associated with benevolent sexism even more strongly than among men. These results extend the previous findings that women are motivated to uphold benevolent sexism and justify the gender-based hierarchy more than men (Sibley et al. 2007a, b, 2009), and, more generally, that members of disadvantaged groups internalize beliefs that maintain social inequality (Jost and Kay 2005) and accept their disadvantaged position when they identity with the superordinate category they represent (Dovidio et al. 2009).

The present results extend and clarify those previous findings indicating that collectively narcissistic women are more likely to endorse benevolent sexism, a set of beliefs that disadvantages them as a group. Women who hold a collectively narcissistic belief about their nation may perceive the society as more hostile toward them because they are likely to associate with sexist men; indeed, objective analyses of the women's situation in Poland confirm such a perception (Human Rights Watch 2019). Thus, women high on national collective narcissism may adopt benevolent sexist beliefs for self-protection (Expósito et al. 2010; Fischer 2006). For those women, it is also difficult to dissociate from the national group which satisfies their self-importance needs (Golec de Zavala et al. 2020; Golec de Zavala and Keenan 2020). Thus, they endorse gender inequality to protect the positive image of the in-group in which their self-importance needs are invested. Women high on national collective narcissism are likely to support oppressive policies regarding women, like women representing the Life and Family Foundation, a proponent of the "Stop abortion" bill (Shukla and Klosok 2020) - the most restrictive abortion law penalizing any case of abortion - or those women who publicly undermine proponents of reproductive women's rights as "fans of killing babies" (Davies 2016, para 13).

In contrast to national collective narcissism across both gender groups, national in-group satisfaction is not associated with sexism and it is negatively associated with tolerance of violence against women. In addition, the analyses of moderation by gender on the relationship between national in-group satisfaction and sexism clarify that, among women, national in-group satisfaction is negatively associated with benevolent and hostile sexism (although the association with hostile sexism is not significant, it is negative and significantly different from the same association among men which is positive). In contrast, national in-group satisfaction is positively associated with both forms of sexism among men (although the association with hostile sexism is not significant). Thus, gender and national in-group satisfaction predict sexism among men. This is a notable qualification of previous results indicating that ingroup satisfaction predicts greater intergroup tolerance (Golec de Zavala et al. 2019). Together with results of Study 1, those results suggest that patriotism is less sexist than national collective narcissism. However, patriotic men need to revise their traditional beliefs about gender in order to reject sexism and support gender equality. 
Importantly, the present results indicate that, in contrast to women who endorse national collective narcissism, women who believe their nation gives reasons to be proud reject benevolent and hostile sexism. Thus, national identity can become a positive social identity from which women can resist sexism. They may be motivated to fight gender inequality to improve their national in-group. This attitude may be exemplified by the grassroots activists behind the Black Friday protests against the violation of women's reproductive rights in Poland (Freedom News 2018) and by women's rights activists and artists who consider themselves Polish but oppose the mainstream traditional beliefs about women (Graff 2019). More generally, the present results indicate the existence of at least two discourses about Polish national identity that are related to strikingly different propositions regarding gender equality and the role of women in the national community.

The results linking Polish in-group satisfaction to rejection of sexism among women are in line with previous findings suggesting that in-group satisfaction predicts positive psychological outcomes that may create psychological resources needed to oppose discrimination. Positive social identification increases self-esteem (Golec de Zavala et al. 2020) and a sense of personal control (Cichocka et al. 2018), and it positively contributes to mental health and emotional resilience (Cruwys et al. 2014; Golec de Zavala 2019; Jetten et al. 2014). The present results align with previous work indicating that individuals with high in-group satisfaction may feel in a position to act on behalf of their in-group to enhance it toward greater benefit of all members (Amiot and Sansfaçon 2011; Jans et al. 2012; Legault and Amiot 2014). Such findings correspond to Erikson's (1968) theorizing that acting on behalf of one's community is a motivation endorsed by people with stable self-esteem and high autonomy. Such people can resist hardship and retribution in the name of improving the group that they value.

\section{Limitations and Future Directions}

Although the present results provide several important new insights into the nature of the association between collective narcissism and sexism, there are some limitations that need to be considered. First, all studies were conducted in Poland. Although, previous studies linked hostile sexism to national (Deckman and Cassese 2019) and religious (Glick et al. 2002) identification in other countries, the present results may reflect the associations existing only in Poland and they may not easily generalize to other national contexts. Future studies would do well to examine the associations among male, religious, and national collective narcissism with sexism in other national contexts.

Next, because they are based on cross-sectional data, the results of our studies do not allow for firm inferences regarding directionality and causality of the tested indirect relationships. Although previous theorizing, longitudinal, and experimental findings indicate that more general beliefs about social identity (specifically, collective narcissism) precede and influence more specific attitudes toward groups (Golec de Zavala et al. 2020), future studies should use longitudinal and experimental designs to determine whether collective narcissism specifically causes sexism and hostility toward women.

\section{Practice Implications}

The present results indicate that collective narcissism is an obstacle to achieving greater gender equality because it is robustly associated with sexism that justifies the existing gender hierarchy. This obstacle is especially problematic among women who endorse national collective narcissism and benevolent sexism. This is because internalising discrimination is detrimental to psychological well-being of people targeted by discrimination. The present results suggest that, among women, this obstacle can be overcome by emphasizing a positive overlap between national collective narcissism and national ingroup satisfaction. National in-group satisfaction is associated with rejection of sexism among women. Additionally, given that national and religious identities in Poland are closely related, sexism also may be reduced by relying on the overlap between religious collective narcissism and intrinsic religious orientation, which is associated with rejection of violence against women among men and women. This reasoning suggests that sexism can be reduced when the prevailing definitions of religious and national identities are changed. Efforts to make equality and justice as principal prescriptions of religious teachings and to link non-narcissistic national pride to the value of tolerance and solidarity and to importance of engaging with local communities may reduce the association between collective narcissism and sexism.

Arguably, reducing sexism may be more difficult among men than among women. Among men, even in-group satisfaction, with reference to gender and national identity, a variable that is typically associated with greater tolerance, is associated with sexism and traditional gender beliefs. Given that men and women reject violence toward women, and national in-group satisfaction is associated with rejection of violence toward women also among men, a starting point for interventions among men should be awareness raising of how traditional sexist beliefs are related to violence against women and emphasizing tolerant prescriptions associated with patriotism.

\section{Conclusions}

Despite their limitations, the present findings provide important new insights into the association between collective narcissism and sexism. First, they link, for the first time known, male collective narcissism to sexism and explain the mechanism underlying this relationship. Moreover, they suggest that 
sexism is linked to religious and national collective narcissism. The convergence of religious, gender, and national collective narcissism in the definition of Polish national identity creates an environment particularly hostile toward gender equality. However, patriotic Polish women, in contrast to women who endorse Polish collective narcissism, actively oppose sexism and can capitalize on their positive identification with the national group to develop emotional resilience while challenging gender inequality.

Funding Work on this article was supported by National Science Centre grant 2017/26/A/HS6/00647 awarded to Agnieszka Golec de Zavala.

Open Access This article is licensed under a Creative Commons Attribution 4.0 International License, which permits use, sharing, adaptation, distribution and reproduction in any medium or format, as long as you give appropriate credit to the original author(s) and the source, provide a link to the Creative Commons licence, and indicate if changes were made. The images or other third party material in this article are included in the article's Creative Commons licence, unless indicated otherwise in a credit line to the material. If material is not included in the article's Creative Commons licence and your intended use is not permitted by statutory regulation or exceeds the permitted use, you will need to obtain permission directly from the copyright holder. To view a copy of this licence, visit http://creativecommons.org/licenses/by/4.0/.

\section{References}

Adorno, T. W., Frenkel-Brunswik, E., Levinson, D. J., \& Sanford, R. N. (1950). The authoritarian personality. New York: Harper.

Aguinis, H. (1995). Statistical power problems with moderated multiple regression in management research. Journal of Management, 21(6), 1141-1158. https://doi.org/10.1016/0149-2063(95)90026-8.

Altemeyer, B., \& Hunsberger, B. (1992). Authoritarianism, religious fundamentalism, quest, and prejudice. International Journal for the Psychology of Religion, 2, 113-133. https://doi.org/10.1207/ s15327582ijpr0202_5.

Altemeyer, B., \& Hunsberger, B. (2004). A revised religious fundamentalism scale: The short and sweet of it. International Journal for the Psychology of Religion, 14, 47-54. https://doi.org/10.1207/ s15327582ijpr1401 4.

Ames, D. R., Rose, P., \& Anderson, C. P. (2006). The NPI-16 as a short measure of narcissism. Journal of Research in Personality, 40(4), 440-450. https://doi.org/10.1016/j.jrp.2005.03.002.

Amiot, C. E., \& Sansfaçon, S. (2011). Motivations to identify with social groups: A look at their positive and negative consequences. Group Dynamics: Theory, Research, and Practice, 15, 105-127. https:// doi.org/10.1037/a0023158.

Amnesty International. (2019, November 29). From slurs to sexual violence, women human rights defenders come under global attack. Retrieved from https://www.amnesty.org/en/latest/news/2019/11/ from-slurs-to-sexual-violence-women-human-rights-defenderscome-under-global-attack/. Accessed 25 June 2020.

Batson, C. D., Flink, C. H., Schoenrade, P. A., Fultz, J., \& Pych, V. (1986). Religious orientation and overt versus covert racial prejudice. Journal of Personality and Social Psychology, 50, 175-181. https://doi.org/10.1037/0022-3514.50.1.175.
Batson, C. D., Schoenrade, P., \& Ventis, W. L. (1993). Religion and the individual: A social-psychological perspective. New York: Oxford University Press.

BBC News. (2018). April 26. Elliot Rodger: How misogynist killer became 'incel hero' Retrieved from: https://www.bbc.com/news/ world-us-canada-43892189. Accessed 25 June 2020.

Beauchamp, Z. (2019, April 23). Our Incel problem. In The highlight by Vox Retrieved from https:/www.vox.com/the-highlight/2019/4/16/ 18287446/incel-definition-reddit.

Bosson, J. K., \& Vandello, J. A. (2011). Precarious manhood and its links to action and aggression. Current Directions in Psychological Science, 20, 82-86. https://doi.org/10.1177/0963721411402669.

Bosson, J. K., \& Vandello, J. A. (2013). Manhood, womanhood, and the importance of context: A reply to commentaries. Psychology of Men \& Masculinity, 14, 125-128. https://doi.org/10.1037/a0032437.

Bosson, J. K., Vandello, J. A., Burnaford, R. M., Weaver, J. R., \& Arzu Wasti, S. (2009). Precarious manhood and displays of physical aggression. Personality and Social Psychology Bulletin, 35, 623-634. https://doi.org/10.1177/0146167208331161.

Burn, S. M., \& Busso, J. (2005). Ambivalent sexism, scriptural literalism, and religiosity. Psychology of Women Quarterly, 29, 412-418. https://doi.org/10.1111/j.1471-6402.2005.00241.x.

Bushman, B. J., Bonacci, A. M., van Dijk, M., \& Baumeister, R. F. (2003). Narcissism, sexual refusal, and aggression: Testing a narcissistic reactance model of sexual coercion. Journal of Personality and Social Psychology, 84, 1027-1040. https://doi.org/10.1037/ 0022-3514.84.5.1027.

Buss, D. E., \& Herman, D. (2003). Globalizing family values: The Christian right in international politics. Minneapolis: University of Minnesota Press.

Case, M. A. (2011). After gender the destruction of man - The Vatican's nightmare vision of the "gender agenda" for law. Pace \& Law Review, 31, 802-817. https://pdfs.semanticscholar.org/77c2/ 488133a2dd629fd381fcd691bceb0c515fca.pdf. Accessed 25 June 2020.

Cichocka, A., Golec de Zavala, A., Marchlewska, M., Bilewicz, M., Jaworska, M., \& Olechowski, M. (2018). Personal control decreases narcissistic but increases non-narcissistic in-group positivity. Journal of Personality, 86(3), 465-480. https://doi.org/10.1111/ jopy. 12328.

Coman, J. (2019, October 5). Family, faith, flag: the religious right and the battle for Poland's soul. Retrieved from https://www. theguardian.com/world/2019/oct/05/family-faith-flag-catholicreligious-right-battle-polands-soul. Accessed 25 June 2020.

Crandall, C. S., Eshleman, A., \& O'Brien, L. (2002). Social norms and the expression and suppression of prejudice: The struggle for internalization. Journal of Personality and Social Psychology, 82, 359378. https://doi.org/10.1037/0022-3514.82.3.359.

Crocker, J., \& Luhtanen, R. (1990). Collective self-esteem and ingroup bias. Journal of Personality and Social Psychology, 58, 60-67. https://doi.org/10.1037/0022-3514.58.1.60.

Cruwys, T., Haslam, S., Dingle, G. A., Haslam, C., \& Jetten, J. (2014). Depression and social identity: An integrative review. Personality and Social Psychology Review, 18, 215-238. https://doi.org/10. $1177 / 1088868314523839$.

Dasgupta, N., \& Rivera, L. M. (2006). From automatic antigay prejudice to behavior: The moderating role of conscious beliefs about gender and behavioral control. Journal of Personality and Social Psychology, 91, 268-280. https://doi.org/10.1037/0022-3514.91.2. 268.

Davies, C. (2016, October). 5th. The Guardian: Poland's abortion ban proposal near collapse after mass pro. https://www.theguardian. com/world/2016/oct/05/polish-government-performs-u-turn-ontotal-abortion-ban. Accessed 25 June 2020.

Davison, A. C., \& Hinkley, D. V. (1997). Bootstrap methods and their application (no. 1). Cambridge, UK: Cambridge University Press. 
Deckman, M., \& Cassese, E. (2019). Gendered nationalism and the 2016 U.S. presidential election: How party, class, and beliefs about masculinity shaped voting behaviour. Politics \& Gender. Advance online publication. https://doi.org/10.1017/s1743923x19000485.

Dovidio, J. F., Gaertner, S. L., \& Saguy, T. (2007). Another view of "we": Majority and minority group perspectives on a common ingroup identity. European Review of Social Psychology, 18, 296-330. https://doi.org/10.1080/10463280701726132.

Dovidio, J. F., Gaertner, S. L., \& Saguy, T. (2009). Commonality and the complexity of "we": Social attitudes and social change. Personality and Social Psychology Review, 13(1), 3-20. https://doi.org/10.1177/ 1088868308326751.

Dyduch-Hazar, K., Mrozinski, B., \& Golec de Zavala, A. (2019). Collective narcissism and in-group satisfaction predict opposite attitudes toward refugees via attribution of hostility. Frontiers in Psychology, 10, 1901. https://doi.org/10.3389/fpsyg.2019.01901.

Ellemers, N., Pagliaro, S., \& Barreto, M. (2013). Morality and behavioural regulation in groups: A social identity approach. European Review of Social Psychology, 24, 160-193. https://doi.org/10. 1080/10463283.2013.841490.

Erikson, E. H. (1968). Identity: Youth and crisis. New York: W. W. Norton.

Expósito, F., Herrera, M. C., Moya, M., \& Glick, P. (2010). Don’t rock the boat: Women's benevolent sexism predicts fears of marital violence. Psychology of Women Quarterly, 34, 36-42. https://doi.org/ 10.1111/j.1471-6402.2009.01539.x.

Fischer, A. R. (2006). Women's benevolent sexism as reaction to hostility. Psychology of Women Quarterly, 30, 410-416. https://doi.org/ 10.1111/j.1471-6402.2006.00316.x.

Fox, J., \& Weisberg, S. (2019). An R companion to applied regression (3rd ed.). Thousand Oaks CA: Sage.

Fowler, K. A., \& Westen, D. (2011). Subtyping male perpetrators of intimate partner violence. Journal of Interpersonal Violence, 26, 607-639. https://doi.org/10.1177/0886260510365853.

Francis, L. J. (2007). Introducing the new indices of religious orientation (NIRO): Conceptualization and measurement. Mental Health, Religion \& Culture, 6, 585-602. https://doi.org/10.1080/ 13674670601035510.

Francis, L. J., Fawcett, B., Linkletter, J., Robbins, M., \& Stairs, D. (2016). Psychological type profile of Canadian Baptist youth leaders: Implications for Christian education. International Journal of Christianity \& Education, 20, 220-233. https://doi.org/10.1177/ 2056997116644264.

Freedom News (2018, March, $14^{\text {th }}$ ). Black Friday protests in Poland take over the streets. https://freedomnews.org.uk/black-friday-protestsin-poland-take-over-the-streets/. Accessed 25 June 2020.

Glick, P., \& Fiske, S. T. (1996). The ambivalent sexism inventory: Differentiating hostile and benevolent sexism. Journal of Personality and Social Psychology, 70, 491-512. https://doi.org/ 10.1037/0022-3514.70.3.491.

Glick, P., \& Fiske, S. T. (1997). Hostile and benevolent sexism: Measuring ambivalent sexist attitudes toward women. Psychology of Women Quarterly, 21, 119-135. https://doi.org/10.1111/j.14716402.1997.tb00104.x.

Glick, P., \& Fiske, S. T. (2001). An ambivalent alliance: Hostile and benevolent sexism as complementary justifications for gender inequality. American Psychologist, 56, 109-118. https://doi.org/10. 1037/0003-066X.56.2.109.

Glick, P., Lameiras, M., \& Castro, Y. R. (2002). Education and Catholic religiosity as predictors of hostile and benevolent sexism toward women and men. Sex Roles, 47, 433-441. https://doi.org/10.1023/ A:1021696209949.

Golec de Zavala, A. (2011). Collective narcissism and intergroup hostility: The dark side of "in-group love." Social and Personality Psychology Compass, 5, 309-320. https://doi.org/10.1111/j.17519004.2011.00351.x.
Golec de Zavala, A. (2019). Collective narcissism and in-group satisfaction are associated with different emotional profiles and psychological wellbeing. Frontiers in Psychology, 10. https://doi.org/10.3389/ fpsyg.2019.00203.

Golec de Zavala, A., \& Cichocka, A. (2012). Collective narcissism and anti-Semitism in Poland. Group Processes and Intergroup Relations, 15, 213-229. https://doi.org/10.1177/ 1368430211420891.

Golec de Zavala, A., Cichocka, A., \& Bilewicz, M. (2013a). The paradox of in-group love: Differentiating collective narcissism advances understanding of the relationship between in-group and out-group attitudes. Journal of Personality, 81, 17-28. https://doi.org/10.1111/j. 1467-6494.2012.00779.x.

Golec de Zavala, A., Cichocka, A., Eidelson, R., \& Jayawickreme, N. (2009). Collective narcissism and its social consequences. Journal of Personality and Social Psychology, 97, 1074-1096. https://doi. org/10.1037/a0016904.

Golec de Zavala, A., Cichocka, A., \& Iskra-Golec, I. (2013b). Collective narcissism moderates the effect of in-group image threat on intergroup hostility. Journal of Personality and Social Psychology, 104, 1019-1039. https://doi.org/10.1037/a0032215.

Golec de Zavala, A., Dyduch-Hazar, K., \& Lantos, D. (2019). Collective narcissism: Political consequences of investing self-worth in the ingroup's image. Political Psychology, 40, 37-74. https://doi.org/ 10.1111/pops. 12569 .

Golec de Zavala, A., Federico, C., Sedikides, C., Guerra, R., Lantos, D., Mrozinski, B., ... Baran, T. (2020). Low self-esteem predicts outgroup derogation via collective narcissism, but this relationship is obscured by in-group satisfaction. Journal of Personality and Social Psychology. 119(3), 741-764 https://doi.org/10.1037/pspp0000260.

Golec de Zavala, A., \& Keenan, O. (2020). Collective narcissism as a framework for understanding of the appeal of right-wing populism. Journal of Theoretical Social Psychology. Advance online publication. https://doi.org/10.1002/jts5.69.

Golec de Zavala, A., \& Lantos, D. (2020). Collective narcissism and its social consequences: The bad and the ugly. Current Directions in Psychological Science, 29, 273-278. https://doi.org/10.1177/ 0963721420917703.

Golec de Zavala, A., Lantos, D., \& Keenan, O. (in press). The angry men? What does the association of populism with misogyny and homophobia tell us about its motivational roots. In J. Forgas, W. Crano, \& K. Fiedler (Eds.), The psychology of populism. Abingdon, UK: Taylor \& Francis.

Golec de Zavala, A., Peker, M., Guerra, R., \& Baran, T. (2016). Collective narcissism predicts hypersensitivity to in-group insult and direct and indirect retaliatory intergroup hostility. European Journal of Personality, 30, 532-551. https://doi.org/10.1002/per. 2067.

Gorsuch, R. L., \& McPherson, S. E. (1989). Intrinsic/extrinsic measurement: I/E-revised and single-item scales. Journal for the Scientific Study of Religion, 28, 348-354. https://doi.org/10.2307/1386745.

Górska, P., Stefaniak, A., Malinowska, K., Lipowska, K., Marchlewska, M., Budziszewska, M., ... Maciantowicz, O. (2019). Too great to act in solidarity: The negative relationship between collective narcissism and solidarity-based collective action. European Journal of Social Psychology, 50, 561-578. https://doi.org/10.1002/ejsp.2638.

Graff, A. (2010). Looking at pictures of gay men: Political uses of homophobia in contemporary Poland. Public Culture, 22, 583-603. https://doi.org/10.1215/08992363-2010-010.

Graff, A. (2019). Claiming the shipyard, the cowboy hat, and the anchor for women: Polish Feminism's dialogue and struggle with National Symbolism. East European Politics and Societies, 33(2), 472-496. https://doi.org/10.1177/0888325419835914.

Grzyb, M. (2019). Making domestic violence visible in Poland. Global Dialogue, 8. Retrieved from http://globaldialogue.isa-sociology.org/ 
making-domestic-violence-visible-in-poland/. Accessed 25 June 2020.

Haggard, M. C., Kaelen, R., Saroglou, V., Klein, O., \& Rowatt, W. C. (2019). Religion's role in the illusion of gender equality: Supraliminal and subliminal religious priming increases benevolent sexism. Psychology of Religion and Spirituality, 11, 392-398. https://doi.org/10.1037/rel0000196.

Hannover, B., Gubernath, J., Schultze, M., \& Zander, L. (2018). Religiosity, religious fundamentalism, and ambivalent sexism toward girls and women among adolescents and young adults living in Germany. Frontiers in Psychology, 9, 2399. https://doi.org/10. 3389/fpsyg.2018.02399.

Hansen, I., Jackson, V., \& Ryder, A. (2018). Religion and oppression: Cross-national and experimental investigations. Religion, Brain \& Behavior, 8, 369-393. https://doi.org/10.1080/2153599X.2017. 1358208 .

Hansen, N., \& Sassenberg, K. (2006). Does social identification buffer or harm? The impact of social identification on anger after illegitimate discrimination. Personality and Social Psychology Bulletin, 32, 983-996. https://doi.org/10.1177/0146167206287639.

Hayes, A. F. (2017). Introduction to mediation, moderation, and conditional process analysis: A regression-based approach (2nd ed.). New York: Guilford Press.

Herek, G. M. (1987). Religious orientation and prejudice: A comparison of racial and sexual attitudes. Personality and Social Psychology Bulletin, 13, 34 44. https://doi.org/10.1177/0146167287131003.

Hogg, M. A., Adelman, J. R., \& Blagg, R. D. (2010). Religion in the face of uncertainty: An uncertainty-identity theory account of religiousness. Personality and Social Psychology Review, 14, 72-83. https:// doi.org/10.1177/1088868309349692.

Human Rights Watch. (2019, February). "The breath of the government on my back" Attacks on women's rights in Poland. Retrieved from https://www.hrw.org/report/2019/02/06/breath-government-myback/attacks-womens-rights-poland. Accessed 25 June 2020

Jans, L., Postmes, T., \& Van der Zee, K. I. (2012). Sharing differences: The inductive route to social identity formation. Journal of Experimental Social Psychology, 48, 1145-1149. https://doi.org/ 10.1016/j.jesp.2012.04.013.

Jaworska, M. (2016). Czym Jest Dojrzała Identyfikacja z Grupa? W Poszukiwaniu komponentów Identyfikacji Grupowej Majacych Pozytywne Konsekwencje dla Grupywłasnej i Relacji Międzygrupowych [what is secure in-group identification? Looking for in-group identification components that lead to ingroup's benefit in-group and positive inter-group relations]. Warsaw: University of Warsaw.

Jetten, J., Haslam, C., Haslam, S. A., Dingle, G., \& Jones, J. M. (2014). How groups affect our health and well-being: The path from theory to policy. Social Issues and Policy Review, 8, 103-130. https://doi. org/10.1111/sipr.12003.

Jost, J. T., \& Banaji, M. R. (1994). The role of stereotyping in systemjustification and the production of false consciousness. British Journal of Social Psychology, 33, 1-27. https://doi.org/10.1111/j. 2044-8309.1994.tb01008.x.

Jost, J. T., \& Kay, A. C. (2005). Exposure to benevolent sexism and complementary gender stereotypes: Consequences for specific and diffuse forms of system justification. Journal of Personality and Social Psychology, 88, 498-509. https://doi.org/10.1037/00223514.88.3.498.

Kay, A. C., Gaucher, D., Peach, J. M., Laurin, K., Friesen, J., Zanna, M. P., \& Spencer, S. J. (2009). Inequality, discrimination, and the power of the status quo: Direct evidence for a motivation to see the way things are as the way they should be. Journal of Personality and Social Psychology, 97, 421-434. https://doi.org/10.1037/a0015997.

Kirkpatrick, S. A., \& Locke, E. A. (1991). Leadership: Do traits matter? Academy of Management Perspectives, 5, 48-60. https://doi.org/10. 5465/ame.1991.4274679.
Kirkpatrick, L. A. (1993). Fundamentalism, Christian orthodoxy, and intrinsic religious orientation as predictors of discriminatory attitudes. Journal for the Scientific Study of Religion, 32, 256-268. https://doi.org/10.2307/1386664.

Korolczuk, E., \& Graff, A. (2018). Gender as "ebola from Brussels": The anticolonial frame and the rise of illiberal populism. Signs: Journal of Women in Culture and Society, 43, 797-821. https://doi.org/10. 1086/696691.

Kościańska, A. (2014a, August 13). Who can be a true pole? In On gender panic. Retrieved from http://visegradrevue.eu/who-can-bea-true-pole-on-gender-panic/. Accessed 25 June 2020.

Kościańska, A. (2014b, December 5). Violence against women In Poland - what tradition has to do with it? Retrieved from http:// visegradrevue.eu/violence-against-women-in-poland-whattradition-has-to-do-with-it/. Accessed 25 June 2020.

Kosterman, R., \& Feshbach, S. (1989). Toward a measure of patriotic and nationalistic attitudes. Political Psychology, 10, 257-274. https:// doi.org/10.2307/3791647.

Kroeper, K. M., Sanchez, D. T., \& Himmelstein, M. S. (2014). Heterosexual men's confrontation of sexual prejudice: The role of precarious manhood. Sex Roles, 70, 1-13. https://doi.org/10.1007/ s11199-013-0306-z.

Leach, C. W., Van Zomeren, M., Zebel, S., Vliek, M. L. W., Pennekamp, S. F., Doosje, B., ... Spears, R. (2008). Group-level self-definition and self-investment: A hierarchical (multicomponent) model of ingroup identification. Journal of Personality and Social Psychology, 95, 144-165. https://doi.org/10.1037/0022-3514.95.1.144.

Legault, L., \& Amiot, C. E. (2014). The role of autonomy in intergroup processes: Toward and integration of self-determination theory and intergroup approaches. In E. Weinstein (Ed.), Human motivation and interpersonal relationships (pp. 159-190). London, UK: Springer. https://doi.org/10.1007/978-94-017-8542-6.

Lowery, B. S., Unzueta, M. M., Knowles, E. D., \& Goff, P. A. (2006). Concern for the in-group and opposition to affirmative action. Journal of Personality and Social Psychology, 90(6), 961-974. https://doi.org/10.1037/0022-3514.90.6.961.

Lyons, P. A., Kenworthy, J. B., \& Popan, J. R. (2010). Ingroup identification and group-level narcissism as predictors of U.S. citizens' attitudes and behavior toward Arab immigrants. Personality and Social Psychology Bulletin, 36, 1267-1280. https://doi.org/10. 1177/0146167210380604.

Maass, A., Cadinu, M., Guarnieri, G., \& Grasselli, A. (2003). Sexual harassment under social identity threat: The computer harassment paradigm. Journal of Personality and Social Psychology, 85, 853870. https://doi.org/10.1037/0022-3514.85.5.853.

Malka, A., Lelkes, Y., Srivastava, S., Cohen, A. B., \& Miller, D. T. (2012). The association of religiosity and political conservatism: The role of political engagement. Political Psychology, 33, 275299. https://doi.org/10.1111/j.1467-9221.2012.00875.x.

Marchlewska, M., Cichocka, A., Łozowski, F., Górska, P., \& Winiewski, M. (2019). In search of an imaginary enemy: Catholic collective narcissism and the endorsement of gender conspiracy beliefs. The Journal of Social Psychology, 159, 1-14. https://doi.org/10.1080/ 00224545.2019 .1586637$.

McCoy, S. K., \& Major, B. (2003). Group identification moderates emotional responses to perceived prejudice. Personality and Social Psychology Bulletin, 29, 1005-1017. https://doi.org/10.1177/ 0146167203253466

McCullough, K., Wong, Y. J., \& Stevenson, N. (2019). Female video game players and the protective effect of feminist identity against internalized misogyny. Sex Roles, 82, 266-276. https://doi.org/10. 1007/s11199-019-01055-7.

Michniewicz, K. S., \& Vandello, J. A. (2015). People judge male sexism more leniently when women emasculate men. Social Psychology, 46, 197-209. 
Mikołajczak, M., \& Pietrzak, J. (2014). Ambivalent sexism and religion: Connected through values. Sex Roles, 70, 387-399. https://doi.org/ 10.1007/s11199-014-0379-3.

Mikołajczak, M., \& Pietrzak, J. (2015). A broader conceptualization of sexism: The case of Poland. In S. Safdar \& N. KosakowskaBerezecka (Eds.), Psychology of gender through the lens of culture: Theories and applications (pp. 169-191). Cham: Springer International Publishing.

Mole, R., Golec de Zavala A., \& Adraq, M. (2020). Polish collective narcissism and homophobia. Revision submitted.

Morf, C. C., Horvath, S., \& Torchetti, L. (2011). Narcissistic self-enhancement: Tales of (successful?) self-portrayal. In M. D. Alicke \& C. Sedikides (Eds.), Handbook of self-enhancement and selfprotection (pp. 399-424). New York: The Guilford Press.

Mouilso, E. R., \& Calhoun, K. S. (2016). Personality and perpetration: Narcissism among college sexual assault perpetrators. Violence Against Women, 22, 1228-1242. https://doi.org/10.1177/ 1077801215622575.

Muthén, L. K., \& Muthén, B. O. (1998-2017). Mplus user's guide (8th ed.). Los Angeles, CA: Muthén \& Muthén.

Netchaeva, E., Kouchaki, M., \& Sheppard, L. D. (2015). A man's (precarious) place: Men's experienced threat and self-assertive reactions to female superiors. Personality and Social Psychology Bulletin, 41, 1247-1259. https://doi.org/10.1177/ 0146167215593491.

North, M. S., \& Fiske, S. T. (2014). Social categories create and reflect inequality: Psychological and sociological insights. In J. T. Cheng, J. L. Tracy, \& C. Anderson (Eds.), The psychology of social status (pp. 243-265). https://doi.org/10.1007/978-1-4939-0867-7_12.

O'Connor, E. C., Ford, T. E., \& Banos, N. C. (2017). Restoring threatened masculinity: The appeal of sexist and anti-gay humor. Sex Roles, 77, 567-580. https://doi.org/10.1007/s11199-017-0761-z.

Prusaczyk, E., \& Hodson, G. (2018). Left-right differences in abortion policy support in America: Clarifying the role of sex and sexism in a nationally representative 2016 sample. Personality and Individual Differences, 127, 22-25. https://doi.org/10.1016/j.paid.2018.01. 030.

Rollero, C., Glick, P., \& Tartaglia, S. (2014). Psychometric properties of short versions of the ambivalent sexism inventory and ambivalence toward men inventory. TPM-Testing, Psychometrics, Methodology in Applied Psychology, 21, 149-159. https://doi.org/10.4473/ TPM21.2.3

Rothwell, J. (2019). Poland drops plan to legalise 'one-off' cases of domestic violence. Retrieved from https://www.telegraph.co.uk/news/ 2019/01/02/poland-drops-plan-legalise-one-off-cases-domesticviolence/. Accessed 25 June 2020.

Ryu, E., \& Cheong, J. (2017). Comparing indirect effects in different groups in single-group and multi-group structural equation models. Frontiers in Psychology, 8, 747. https://doi.org/10.3389/fpsyg. 2017.00747.

Schatz, R. T., Staub, E., \& Lavine, H. (1999). On the varieties of national attachment: Blind versus constructive patriotism. Political Psychology, 20, 151-174. https://doi.org/10.1111/0162-895X.0014.

Shukla, S., \& Klosok, A. (2020, April). CNN World: Poland debates abortion bill amid coronavirus lockdow. Retrieved from https:// edition.cnn.com/2020/04/15/world/poland-abortion-law-intl/index. html. Accessed 25 June 2020.

Sibley, C. G., Overall, N. C., Duckitt, J., Perry, R., Milfont, T. L., Khan, S. S., ... Robertson, A. (2009). Your sexism predicts my sexism:
Perceptions of men's (but not women's) sexism affects one's own sexism over time. Sex Roles, 60, 682-693. https://doi.org/10.1007/ s11199-008-9554-8.

Sibley, C. G., Overall, N. C., \& Duckitt, J. (2007a). When women become more hostilely sexist toward their gender: The systemjustifying effect of benevolent sexism. Sex Roles, 57(9-10), 743754. https://doi.org/10.1007/s11199-007-9306-1.

Sibley, C. G., Wilson, M. S., \& Duckitt, J. (2007b). Antecedents of men's hostile and benevolent sexism: The dual roles of social dominance orientation and right-wing authoritarianism. Personality and Social Psychology Bulletin, 33(2), 160-172. https://doi.org/10.1177/ 0146167206294745.

Sidanius, J., \& Pratto, F. (1999). Social dominance: An intergroup theory of social hierarchy and oppression. Cambridge, UK: Cambridge University Press.

Staub, E. (1997). Blind versus constructive patriotism: Moving from embeddedness in the group to critical loyalty and action. In D. Bar-Tal \& E. Staub (Eds.), Nelson-hall series in psychology. Patriotism: In the lives of individuals and nations (pp. 213-228). Chicago, IL: Nelson-Hall Publishers.

Templeton, G. F. (2011). A two-step approach for transforming continuous variables to normal: Implications and recommendations for IS research. Communications of the Association for Information Systems, 28(1), 41-58. https://doi.org/10.17705/1CAIS.02804.

Tinkler, J. E. (2013). How do sexual harassment policies shape gender beliefs? An exploration of the moderating effects of norm adherence and gender. Social Science Research, 42, 1269-1283. https://doi. org/10.1016/j.ssresearch.2013.05.002.

Topidi, K. (2019). Religious freedom, national identity, and the polish Catholic Church: Converging visions of nation and god. Religions, 10, 293-312. https://doi.org/10.3390/rel10050293.

United Nations Development Programme. (2019). 2020 human development perspectives. Tackling social norms a game changer for gender inequalities. Retrieved from http://hdr.undp.org/en/GSNI. Accessed 25 June 2020

Vandello, J. A., Bosson, J. K., Cohen, D., Burnaford, R. M., \& Weaver, J. R. (2008). Precarious manhood. Journal of Personality and Social Psychology, 95, 1325-1339. https://doi.org/10.1037/a0012453.

Williams, Z. (2018, April 25). 'Raw hatred': Why the 'incel' movement targets and terrorises women. Retrieved from https://www. theguardian.com/world/2018/apr/25/raw-hatred-why-incelmovement-targets-terrorises-women. Accessed 25 June 2020.

Yip, T. (2009). Simultaneously salient Chinese and American identities: An experience sampling study of self-complexity, context and positive mood among Chinese young adults. Cultural Diversity and Ethnic Minority Psychology, 15, 285-294. https://doi.org/10.1037/ a0013937.

Zeigler-Hill, V., Enjaian, B., \& Essa, L. (2013). The role of narcissistic personality features in sexual aggression. Journal of Social and Clinical Psychology, 32, 186-199. https://doi.org/10.1521/jscp. 2013.32.2.186.

Zhang, Z. (2014). Monte Carlo based statistical power analysis for mediation models: Methods and software. Behavior Research Methods, 46, 1184-1198. https://doi.org/10.3758/s13428-013-0424-0.

Publisher's Note Springer Nature remains neutral with regard to jurisdictional claims in published maps and institutional affiliations. 